\title{
Prevalent sequences in the human genome can form mini i- motif structures at physiological $\mathrm{pH}$.
}

\author{
Bartomeu Mir ${ }^{\ddagger}$, Israel Serrano ${ }^{\dagger}$, Diana Buitrago ${ }^{\&}$, Modesto Orozco ${ }^{\&} \%$, Núria Escaja ${ }^{\ddagger}, *$ and Carlos \\ González ${ }^{\dagger}, *$. \\ †Instituto de Química Física 'Rocasolano', CSIC, Serrano 119, 28006 Madrid, Spain \\ * Inorganic and Organic Chemistry Department, Organic Chemistry Section, and IBUB, University of Barcelona, Martí i \\ Franquès 1-11, 08028 Barcelona, Spain. \\ ${ }^{\&}$ Institute for Research in Biomedicine (IRB Barcelona), The Barcelona Institute of Science and Technology (BIST). 08028 \\ Barcelona, Spain \\ ${ }^{\%}$ Departament de Bioquímica i Biomedicina. Facultat de Biología. Universitat de Barcelona, 08028 Barcelona, Spain \\ ${ }^{\S}$ BIOESTRAN associated unit UB-CSIC.
}

\section{Supporting Information Placeholder}

\begin{abstract}
We report here the solution structure of several repetitive DNA sequences containing d(TCGTTCCGT) and related repeats. At physiological $\mathrm{pH}$, these sequences fold into an imotif like quadruplexes in which every two repeats a globular structure is stabilized by two hemiprotonated $\mathrm{C}: \mathrm{C}^{+}$base pairs, flanked by two minor groove tetrads resulting from the association of $\mathrm{G}: \mathrm{C}$ or $\mathrm{G}: \mathrm{T}$ base pairs. The interaction between the minor groove tetrads and the nearby $\mathrm{C}: \mathrm{C}^{+}$base pairs affords a strong stabilization, which results in effective $\mathrm{pH}_{\mathrm{T}}$ values above 7.5. Longer sequences with more than two repeats are able to fold in tandem, forming a rosary bead-like structure. Bioinformatics analysis shows that these sequences are prevalent in the human genome, and are present in development-related genes.
\end{abstract}

Repetitive DNA sequences are attracting much scientific attention because of their ability to induce genetic instabilities, which ultimately can lead to human diseases. Although the molecular mechanism of these genetic instabilities is not well understood, it has been suggested that it can be related to the tendency of repetitive sequences to adopt non B-DNA structures, ${ }^{[1]}$ such as hairpins, Z-DNA or quadruplexes. Repetitive sequences containing guanine tracts have been extensively studied because of their occurrence in telomeric regions and their ability to fold into G-quadruplexes. Under acidic conditions, their complementary C-rich strands can form i-motif structures. ${ }^{[2]}$ Although a number of repetitive sequences fold into this motif, ${ }^{[3]}$ and recent studies reveal the active role of i-motifs in gene transcription regulation, ${ }^{[4]}$ this class of non-canonical structures has been less studied than others due to its low stability at physiological conditions.

The i-motif is a four-stranded structure formed by the association of two parallel-stranded duplex through hemi-protonated $\mathrm{C}: \mathrm{C}^{+}$base pairs. The two duplexes are intercalated in opposite orientations. Since i-motif formation requires cytosine protonation, these structures are usually stable only at acidic pH. However, recent studies have shown that some particular sequences may be stable at neutral conditions. ${ }^{[5]}$ I-motif structures can be stabilized by external agents, such as molecular crowding agents ${ }^{[6]}$ or by the appropriate chemical modifications. ${ }^{[7]}$ Capping interactions at the ends of the $\mathrm{C}: \mathrm{C}^{+}$stack also play an important role in i-motif stability. In a previous study, we showed that minor groove $\mathrm{G}: T: G: T$ tetrads are excellent capping elements of $\mathrm{C}: \mathrm{C}^{+}$stacks. $^{[8]}$ These tetrads result from the association of two G:T mismatches through their minor groove side, and have been found in $\mathrm{i}$ motifs $^{[9]}$ and in other structures. ${ }^{[10]}$ This family of tetrads have been also observed with Watson-Crick $G: C^{[11]}$ and $A: T^{[12]}$ base pairs (G:C:G:C and A:T:A:T), as well as with combinations of $\mathrm{G}: \mathrm{C}, \mathrm{A}: \mathrm{T}$ and $\mathrm{G}: \mathrm{T}$ base pairs. ${ }^{[10,13]}$

In this paper, we study several repetitive sequences designed to form small i-motifs based on interactions between $\mathrm{C}: \mathrm{C}^{+}$base pairs and minor groove tetrads. We found that the combination of these two secondary structural elements renders a very unique i-motif like structure of an extraordinary stability under physiological conditions.

Table 1. Melting temperature and $\mathrm{pH}_{\mathrm{T}}$ values of different oligonucleotides studied in this paper. Experimental conditions: [oligonucleotide] $=3.5 \mu \mathrm{M}, 10 \mathrm{mM}$ sodium phosphate, $\mathrm{pH} 7$.

\begin{tabular}{|c|c|c|c|}
\hline Name & Sequence & $\mathrm{pH}_{\mathrm{T}}$ & $\mathrm{T}_{\mathrm{m}}\left({ }^{\circ} \mathrm{C}\right)$ \\
\hline LL1 & $d(L-T-L)$ & n.d. & 24.3 \\
\hline LL2 & $\mathrm{d}\left(\mathrm{L}-\mathrm{T}_{2}-\mathrm{L}\right)$ & n.d. & 27.9 \\
\hline LL3 & $\mathrm{d}\left(\mathrm{L}-\mathrm{T}_{3}-\mathrm{L}\right)$ & 7.8 & 32.1 \\
\hline LL4 & $\mathrm{d}\left(\mathrm{L}-\mathrm{T}_{4}-\mathrm{L}\right)$ & 7.9 & 28.4 \\
\hline LL5 & $\mathrm{d}\left(\mathrm{L}-\mathrm{T}_{5}-\mathrm{L}\right)$ & n.d. & 25.4 \\
\hline LL6 & $\mathrm{d}\left(\mathrm{L}-\mathrm{T}_{6}-\mathrm{L}\right)$ & n.d. & 23.3 \\
\hline LL7 & $\mathrm{d}\left(\mathrm{L}-\mathrm{T}_{7}-\mathrm{L}\right)$ & n.d. & 21.7 \\
\hline LL3rep & $\mathrm{d}\left(\mathrm{L}-\mathrm{T}_{3}-\mathrm{L}-\mathrm{T}_{3}-\mathrm{L}-\mathrm{T}_{3}-\mathrm{L}\right)$ & 7.6 & 23.7 \\
\hline LL3long & $\mathrm{d}\left(\mathrm{L}-\mathrm{T}_{3}-\mathrm{L}-\mathrm{T}_{6}-\mathrm{L}-\mathrm{T}_{3}-\mathrm{L}\right)$ & 7.5 & 23.0 \\
\hline L: TCGT & & & \\
\hline
\end{tabular}

The DNA oligonucleotides studied here are shown in Table 1. Their sequences are similar to those that result from connecting the two subunits of the dimeric structure of d(TCGTTTCGT) with poly-thymidine linkers of different lengths. ${ }^{[8]}$ The resulting con- 
struction may adopt different topologies that would be difficult to distinguish in a sequence with perfect TCGT repeats. Thus, to facilitate the assignment of the NMR spectra and to discriminate between possible topologies, we focused on related sequences containing d(TCGTTCCGT) repeats, named as $\mathbf{L}$. These repeats can form different minor groove tetrads depending on the folding pattern, i.e. either two mixed G:C:G:T tetrads or one G:C:G:C and one G:T:G:T tetrad (Figure S1). Interestingly, the NMR spectra of all these sequences at $\mathrm{pH} 7$ exhibit the distinctive imino signals of hemiprotonated $\mathrm{C}: \mathrm{C}^{+}$base pairs (around $15 \mathrm{ppm}$ ), together with imino resonances characteristic of GC Watson-Crick base pairs (13 ppm) and additional narrow signals in the 10-11 ppm region, where GT mismatches are found (Figures 1D, S2 and S3). NMR spectra recorded at different temperatures indicate that the structures are stable at neutral $\mathrm{pH}$ (see Figure S2 and S3). This is confirmed by CD spectra, which, under the same neutral conditions, exhibit a positive band around $265 \mathrm{~nm}$ (Figure 1C) that disappears upon temperature increases (see Figure S2 and S3). The CD spectra are distinct from those seen in most i-motif structures with the characteristic band at $285 \mathrm{~nm}$ shifted to lower wavelength. These $\mathrm{CD}$ spectra resemble those observed in the dimeric structure of $\mathrm{d}<$ pTCGTTTCGT $>$ and other structures stabilized by slipped minor groove tetrads. ${ }^{[8,10,11 \mathrm{a}]}$ Melting experiments were conducted by following the decrease of the maximum ellipticity (Figure 1A). The resulting Tm values are shown in Table 1 .

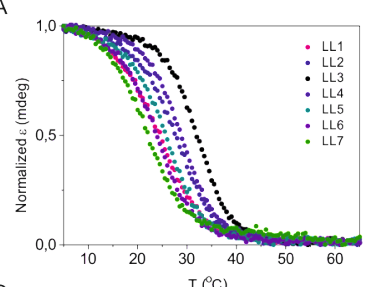

C
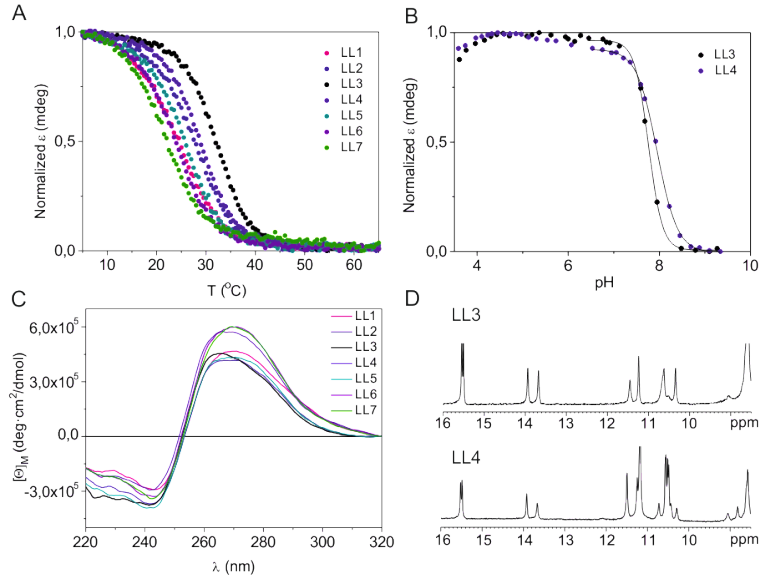

D LL3
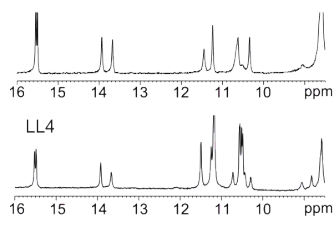

Figure 1. (A) CD melting experiments of LL1-7 at $\mathrm{pH} \mathrm{7,} \mathrm{B)} \mathrm{pH}$ titration of LL3 and LL4, C) CD spectra of the different sequences, and D) exchangeable protons region of the ${ }^{1} \mathrm{H}-\mathrm{NMR}$ spectra of LL3 and LL4 at $\mathrm{T}=5^{\circ} \mathrm{C}, 10 \mathrm{mM}$ phosphate buffer, $\mathrm{pH}$. [oligonucleotide] $=3.5 \mu \mathrm{M}$ for $\mathrm{CD} / \mathrm{UV}$ and $1 \mathrm{mM}$ for NMR.

The comparison of the apparent $\mathrm{T}_{\mathrm{m}}$ and $\mathrm{pH}_{\mathrm{T}}$ values for the different oligonucleotides reveals a clear dependence on the polythymidine loop length, with LL3 and LL4 being the most stable. Based on this, we focused on these two oligonucleotides for a more detailed structural study.

As expected for i-motif like structures, their thermal stability is pH-dependent. UV melting experiments recorded at two different $\mathrm{pHs}$ are shown in Figure $\mathrm{S} 4$. The effective $\mathrm{pH}_{\mathrm{T}}$ values (midpoint of the $\mathrm{pH}$ transition) were estimated by carrying out a CDmonitored $\mathrm{pH}$ titration. As shown in Table 1 and $\mathrm{S} 1, \mathrm{pH}_{\mathrm{T}}$ values are surprisingly high for structures containing hemiprotonated $\mathrm{C}: \mathrm{C}^{+}$base pairs, although not completely unprecedented. ${ }^{[5]}$

To determine the molecularity of the structure, melting experiments were run at different oligonucleotide concentrations. The results shown in Figure S5 clearly indicate the formation of monomeric structures, since the $T_{m}$ values do not depend on DNA concentration. This is confirmed by electrophoretic gel experiments shown in Figure S6. The electrophoretic mobility of sequences containing two repeats of the sequence $\mathbf{L}$ is compared with a sequence containing four repeats (LL3rep) in addition to
poly-dT references. For all the LL sequences, the observed spots are in the range of dT15 and dT30 and migrate significantly faster than LL3rep, confirming the formation of unimolecular structures.

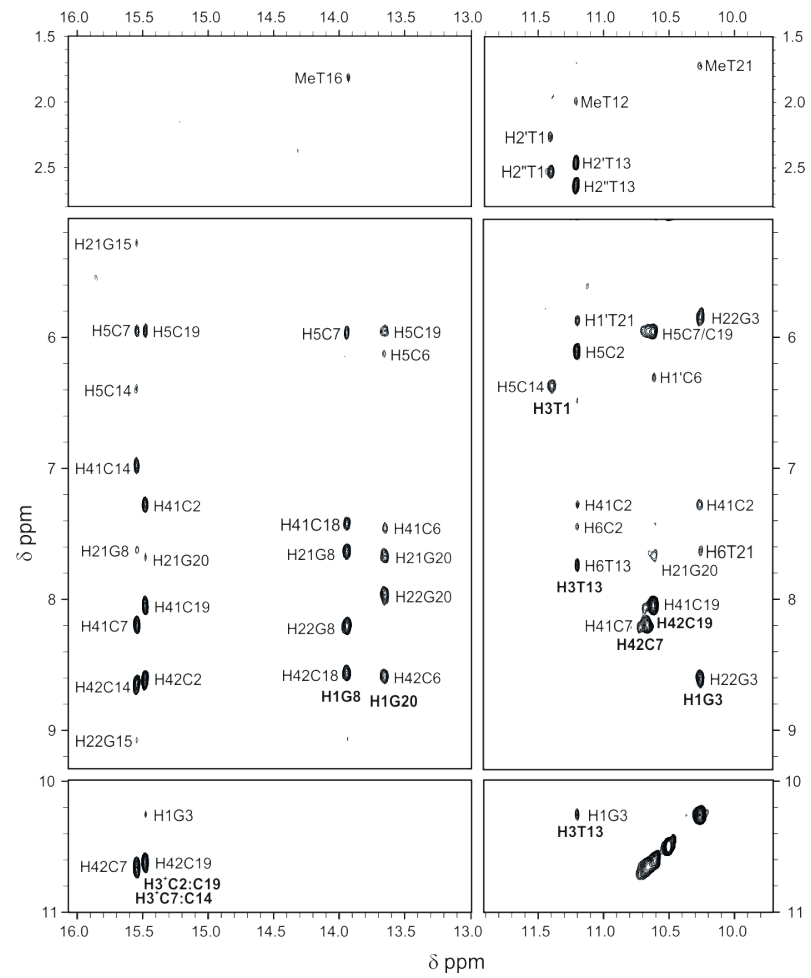

Figure 2. Exchangeable protons regions of the NOESY spectra (mixing time $=150 \mathrm{~ms}$ ) of $1 \mathrm{mM} \mathrm{LL} 3, \mathrm{~T}=5^{\circ} \mathrm{C}, 10 \mathrm{mM}$ phosphate buffer, $\mathrm{pH} 7$.

Two-dimensional NMR spectra of LL3 and LL4 were recorded and fully assigned. Cytosine residues were assigned by analysing several constructions in which particular cytosines were substituted by $5-\mathrm{Me}-\mathrm{dC}\left({ }^{\mathrm{m}} \mathrm{C}\right)$ residues (see Figures $\mathrm{S} 7-10$ for details). The spectra are of excellent quality and show narrow lines and good dispersion of exchangeable signals (see Figures 2, S11 and S12). In both cases the main spectral features are identical. Two hemiprotonated imino signals are shown around $15.5 \mathrm{ppm}$. Each of these signals shows cross-peaks with two pairs of amino protons. Two guanine imino signals are found around 13-14 ppm, the characteristic region of Watson-Crick G:C base pairs, and exhibit cross-peaks with the amino protons of two cytosines. The other guanine imino signals are found upfield, ( 10-12 ppm). These signals show cross-peaks with imino protons of two thymine residues, indicating the formation of G:T base pairs (see Figure 2 and S11, imino proton of G15 in LL3 is not observed). The formation of G:C:G:T tetrads is supported by a number of crosspeaks between amino and H1' protons of different guanines. Interestingly, significant differences are found in the chemical shift of amino protons of cytosine residues involved in the $\mathrm{C}: \mathrm{C}^{+}$ base pairs. Those belonging to the cytidine residues stacked with the G:C base pair of the tetrad exhibit downfield values. Full details on the assignment procedures are given in the supplementary material. The chemical shifts are listed in Tables S2-5.

The three-dimensional structure of LL3 was determined on the basis of approximately 125 experimental distance constraints by using restrained molecular dynamics methods (see Supplementary Information (SI). and Tables S6 and S7.). Except for some loop residues, the structures are very well-defined with an RMSD of $0.8 \AA$. The structures consist of a short stack of two hemiprotonated $\mathrm{C}: \mathrm{C}^{+}$base pairs, surrounded by two minor groove $\mathrm{G}: \mathrm{C}: \mathrm{G}: \mathrm{T}$ tetrads (see Figure 3). Adjacent guanines and cytosines in these tetrads are connected by two-thymine loops, being the first thy- 
mines in well-defined positions capping the tetrads, whereas the second ones are disordered. The two segments containing the d(TCGTTCCGT) repeats are oriented forming an X-shape when seen from the minor groove side (Figure 3). The loop connecting the two repeats is relatively disordered in both structures. As previously seen in i-motifs and other structures stabilized by minor groove tetrads, the minor grooves are extremely narrow with a number of inter-strand sugar-sugar contacts. These favorable contacts, together with the positive charge of the hemiprotonated base pairs, help alleviate the electrostatic repulsion arising between nearly phosphate groups on contiguous strands. Furthermore, the structure is stabilized by a number of hydrogen bonds, arising from two $\mathrm{C}: \mathrm{C}^{+}$, two $\mathrm{G}: \mathrm{C}$ and two $\mathrm{G}: \mathrm{T}$ base pairs, in addition to those from $\mathrm{G}: \mathrm{G}$ interaction in the $\mathrm{G}: \mathrm{C}: \mathrm{G}: \mathrm{T}$ tetrads.

These two guanines lay exactly on top of the $\mathrm{C}: \mathrm{C}^{+}$base pair, as shown in Figures 3 and S13. These stacking interactions further stabilize the structure and, most probably, contribute to maintain the cytosines hemiprotonated at unusually high $\mathrm{pH}$ values. The key importance of this interaction is reflected in the temperature dependence of the exchangeable protons spectra. As shown in Figures S2 and S3, imino signals of the G:C:G:T tetrads and the $\mathrm{C}: \mathrm{C}^{+}$base pairs disappear at the same temperature, indicating that these two structural elements unfold concomitantly.

The lateral two-residue loops are very similar to those found in the dimeric structure of $\mathrm{d}<\mathrm{pTCGTTTCGTT}>$ and other related structures connecting the sides of minor grove tetrads. Previous studies showed that the optimal number of residues connecting the two sides of this kind of tetrads is two. ${ }^{[14]}$ More interesting is the effect of the length of longer loop connecting the two repeats. The NMR spectra of the different oligonucleotides studied here clearly indicate that similar structures are formed regardless of the number of residues in this loop (Figures S2 and S3). Although the loop length affects the stability of the structure, as mentioned above, our results indicate that this motif is rather tolerant of different loop lengths.

Slipped G:C:G:C tetrads are structurally very similar to G:C:G:T and G:T:G:T tetrads. To check whether these tetrads can also stabilize this minimal i-motif, two sequences, containing $\mathrm{T} \leftarrow \rightarrow \mathrm{C}$ mutations at positions 1 and 6 of the $\mathbf{L}$ repeat were studied. The resulting repeats d(TCGTTTCGT) and $\mathrm{d}(\mathrm{CCGTTCCGT)}$, named as $\mathbf{M}$ and $\mathbf{N}$, respectively, were connected with a four thymine loop. The NMR spectra of these oligonucleotides (MM4 and NN4) are shown in Figure S14. In addition to the imino signals from hemiprotonated $\mathrm{C}: \mathrm{C}^{+}$base pairs, imino proton resonances from $\mathrm{G}$ : $\mathrm{C}$ bases pair (in NN4) and from G:T mismatches (MM4) are observed. These NMR data clearly indicate that their overall structures exhibit the same features as LL3 and LL4.
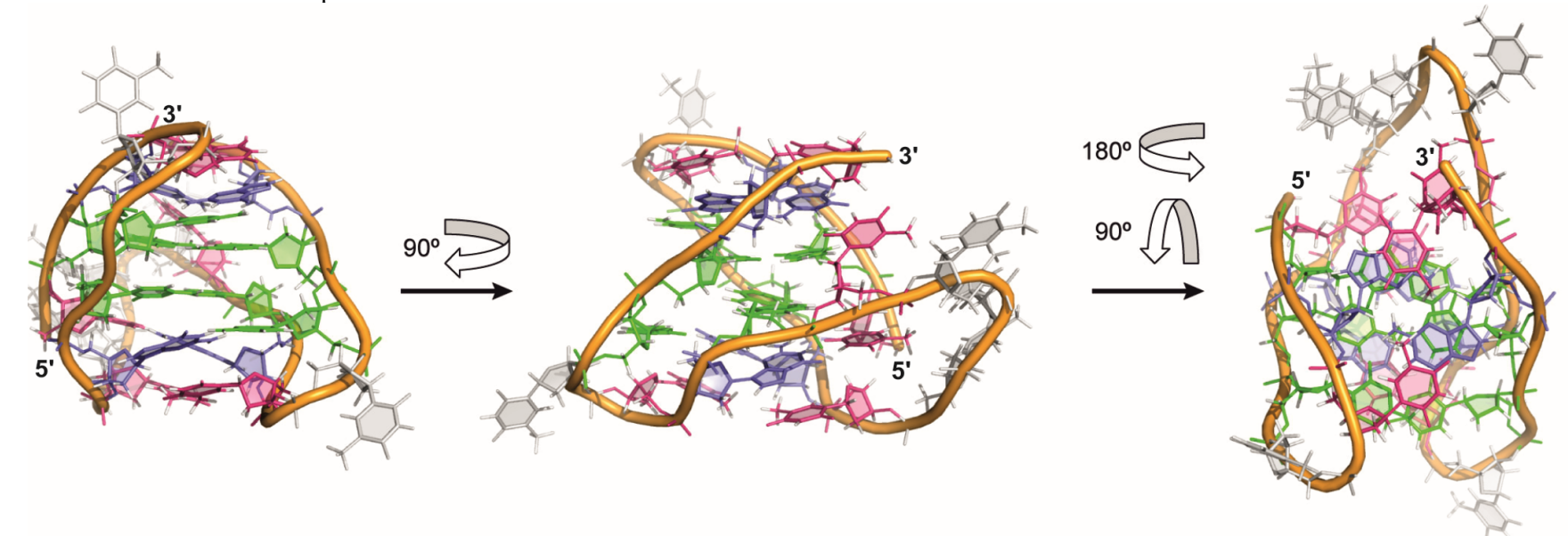

Figure 3. Different views of the calculated structure of LL3. Cytosines are shown in green; guanines in blue; thymines with a well-defined structure are in magenta and the rest in grey. PDB code 5OGA.

Finally, we tested whether this motif can fold in tandem. Two constructions (LL3rep and LL3long), consisting of four repeats of $\mathrm{d}$ (TCGTTCCGT) connected with poly-T loops of different lengths were prepared. Most interestingly, the NMR and CD spectra recorded at $\mathrm{pH} 7$ show the same general features observed for LL3 (Figure 4C and 4D) and similar $\mathrm{pH}$ and thermal stability as that found for LL1-7 sequences (see Table 1 and Figure S15). We must conclude that this structural motif can occur in tandem, forming rosary bead-like structures as shown in Figure 4E. The model shown in this figure was built from a sequence with $6 \mathrm{~L}$ repeats, forming a domain with the structure of LL3 every two repeats. As working hypothesis, we have assumed that the loop connecting each of the units is disordered, and no interaction occurs between each individual unit. Although this is consistent with our NMR data, more work is now in progress in our group to fully confirm these assumptions.

Although a more systematic study is necessary to fully assess the sequential requirements for the formation of these structures, the fact that most thymines in the loops are disordered suggests that their contribution to the stability is not significant, and they might be substituted by other nucleotides. C:G steps at the appropriate distance in the sequence to bring two $\mathrm{G}: \mathrm{C}$ or $\mathrm{G}: \mathrm{T}$ base pairs into register for a minor groove tetrad formation besides $\mathrm{C}: \mathrm{C}^{+}$ base pair is probably the necessary sequential requirement. Based on these premises, a consensus motif can be established as $\mathrm{d}\left(\mathrm{YCG}(\mathrm{XX}) \mathrm{YCG}\left(\mathrm{X}_{\mathrm{n}}\right) \mathrm{YCG}(\mathrm{XX}) \mathrm{YCG}\right)$, where $\mathrm{X}$ can be any nucleotide.

We mapped this consensus motif with $\mathrm{n}$ from 4 to 10 bases (forcing exact matching) to the hg19 version (UCSC GRCh37, $\mathrm{Feb} / 2009)$ of the human genome, finding 4971 hits, more than expected from a random model ( $\mathrm{p}$ value $<10^{-28}$ ). The most common length for the connection loop is 7 nucleotides (which appear twice more than expected, p-value $<10^{-113}$ ). Very interestingly, regions susceptible to form mini i-motif structures are not randomly distributed in the genome, but are very localized in regulatory regions, very close to the transcription start site (TSS; see Figure S16), especially in promoters and 5'UTRs (see Table S8). Gene ontology analysis $(\mathrm{GO})^{[15]}$ reveals that the consensus motif is over-represented (again with a very high statistical confidence) in development-related genes (see Table S9). 


\section{AUTHOR INFORMATION}

\section{Corresponding Author}

nescaja@ub.edu; cgonzalez@iqfr.csic.es.
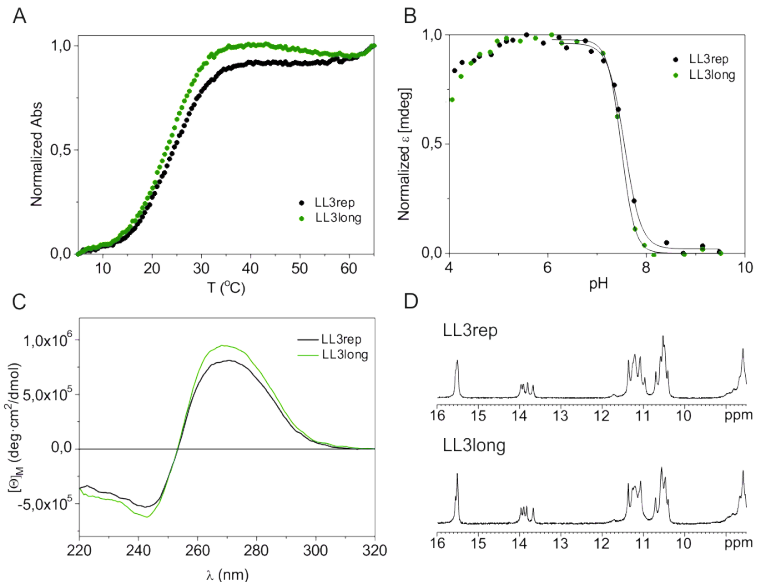

DL3rep

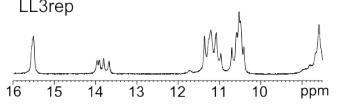

LL3long
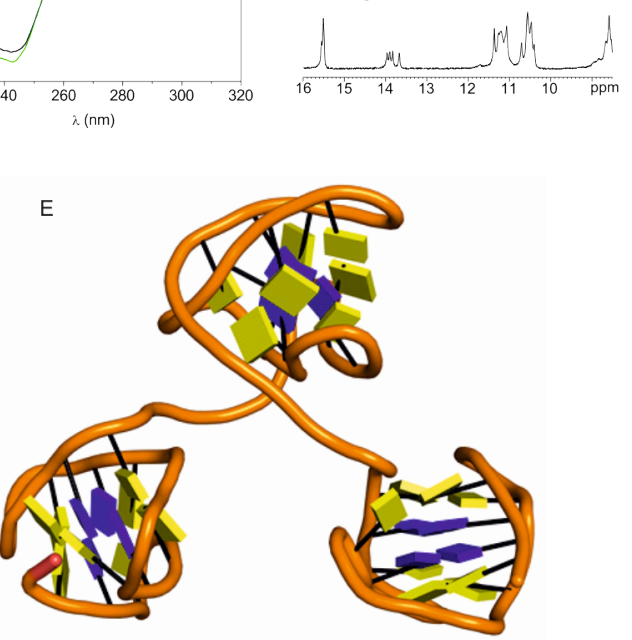

Figure 4. Studies on LL3rep and LL3long (A) UV melting experiments B) $\mathrm{pH}$ titration $\mathrm{C}$ ) $\mathrm{CD}$ spectra and $\mathrm{D}$ ) exchangeable protons region of the ${ }^{1} \mathrm{H}-\mathrm{NMR}$ at $\mathrm{T}=5^{\circ} \mathrm{C}, 10 \mathrm{mM}$ phosphate buffer, $\mathrm{pH}$. [oligonucleotide] $=3.5$ $\mu \mathrm{M}$ for $\mathrm{UV} / \mathrm{CD}$ and $1 \mathrm{mM}$ for NMR. E) Model of the formation of three mini i-motifs in tandem.

In summary, we have found that single stranded DNA can fold into tandem repeats of a novel i-motif like quadruplex structures at physiological $\mathrm{pH}$. Bioinformatics analysis very strongly suggest that mini i-motif forming sequences are not only prevalent in the human genome, but are present in key regulatory elements associated to genes which need to be tightly controlled during development and differentiation. All these findings very strongly support an important functional role for the suggested structure. It is tempting to believe, that as found for telomeres, the equilibrium between B-type duplex and mini i-motif can help in the control of the expression of these development-related genes.

\section{ASSOCIATED CONTENT}

\section{Supporting Information.}

Detailed descriptions of the experimental procedures and NMR assignments; 10 tables with assignment, calculation statistics, and structural analysis; 16 figures showing UV melting, CD, electrophoretic experiments, NMR data, and details on the structural models and sequence analysis. This material is available free of charge via the Internet at http://pubs.acs.org.

\section{Funding Sources}

No competing financial interests have been declared. This work was supported by the MINECO grants CTQ2014-52658-R, BFU2014-61670-EXP and BFU2014-52864-R. The European Research Council (ERC SimDNA), the European Union's Horizon 2020 program (grant No 676556), Biomolecular and Bioinformatics Resources Platform (ISCIII PT 13/0001/0030), and the MINECO Severo Ochoa Award of Excellence (Government of Spain) (awarded to IRB Barcelona). B.M. was supported by an ADR University of Barcelona fellowship.

\section{REFERENCES}

[1] a) A. Bacolla, R. D. Wells, Molecular carcinogenesis 2009, 48 , 273-285; b) R. D. Wells, Trends Biochem Sci 2007, 32, 271-278.

[2] a) K. Gehring, J-L. Leroy, M. Guéron, Nature 1993, 363, 561565 ; b) S. Benabou, A. Aviñó, R. Eritja, C. González, R. Gargallo, RSC Adv. 2014, 4, 26956-26980; c) H. A. Day, P. Pavlou, Z. A Waller, Bioor. Med. Chem. 2014, 22, 4407-4418.

[3] a) A. T. Phan, M. Guéron, J. L. Leroy, J Mol Biol 2000, 299, 123-144; b) M. Garavís, N. Escaja, V. Gabelica, A. Villasante, C. González, Chem-Eur J 2015, 21, 9816-9824; c) Y. W. Chen, C. R. Jhan, S. Neidle, M. H. Hou, Angew Chem Int Ed 2014, 53, 1068210686.

[4] a) S. Kendrick, H. J. Kang, M. P. Alam, M. M. Madathil, P. Agrawal, V. Gokhale, D. Z. Yang, S. M. Hecht, L. H. Hurley, J. Am. Chem. Soc. 2014, 136, 4161-4171; b) H. J. Kang, S. Kendrick, S. M. Hecht, L. H. Hurley, J. Am. Chem. Soc. 2014, 136, 4172-4185.

[5] a) J. A. Brazier, A. Shah, G. D. Brown, Chem. Comm. 2012, 48 , 10739-10741; b) A. M. Fleming, Y. Ding, R. A. Rogers, J. Zhu, J. Zhu, A. D. Burton, C. B. Carlisle, C. J. Burrows, J. Am. Chem. Soc 2017, 139, 4682-4689; c) E. P. Wright, J. L. Huppert, Z. A. E. Waller, Nucleic Acids Res. 2017, 45, 2951-2959; d) A. Kovanda, M. Zalar, P. Sket, J. Plavec, B. Rogelj, Sci. Rep. 2015, 5, 17944.

[6] J. Cui, P. Waltman, V. H. Le, E. A. Lewis, Molecules 2013, 18 $12751-12767$

[7] H. Abou Assi, R. W. Harkness, N. Martin-Pintado, C. J. Wilds, R. Campos-Olivas, A. K. Mittermaier, C. González, M. J. Damha, Nucleic Acids Res. 2016, 44, 4998-5009.

[8] N. Escaja, J. Viladoms, M. Garavís, A. Villasante, E. Pedroso, C. González, Nucleic Acids Res. 2012, 40, 11737-11747.

[9] J. Gallego, S. H. Chou, B. R. Reid, J. Mol. Biol. 1997, 273 840-856.

[10] J. Viladoms, N. Escaja, E. Pedroso, C. González, Bioor. Med. Chem. 2010, 18, 4067-4073.

[11] a) N. Escaja, I. Gómez-Pinto, E. Pedroso, C. González, J. Am. Chem. Soc. 2007, 129, 2004-2014; b) J. Viladoms, N. Escaja, M. Frieden, I. Gómez-Pinto, E. Pedroso, C. González, Nucleic Acids Res. 2009, 37, 3264-3275; V. Kocman, J. Plavec, Nat. Commun. 2017, 8 , 15355.

[12] N. Escaja, E. Pedroso, M. Rico, C. González, J. Am. Chem. Soc. 2000, 122, 12732-12742.

[13] N. Escaja, J. L. Gelpi, M. Orozco, M. Rico, E. Pedroso, C. González, J. Am. Chem. Soc. 2003, 125, 5654-5662.

[14] N. Escaja, I. Gómez-Pinto, J. Viladoms, E. Pedroso, C. González, Org. Biomol. Chem. 2013, 11, 4804-4810.

[15] McLean, C.Y., Bristor, D., Hiller, M., Clarke, S.L., Schaar, B.T., Lowe, C.B., Wenger, A.M., and Bejerano, G. Nat. Biotech., 2010, 28, 495-501. 


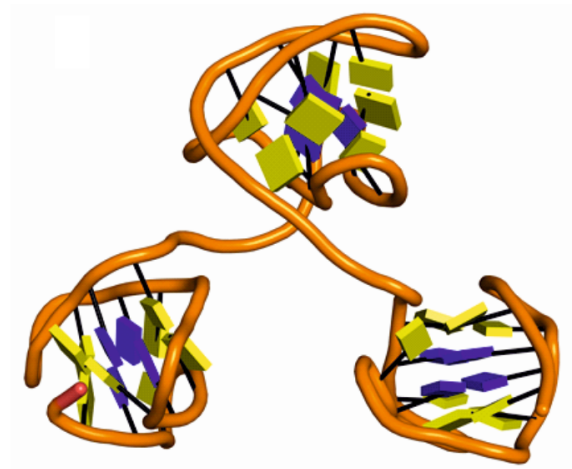

Insert Table of Contents artwork here 


\title{
ELECTRONIC SUPPORTING INFORMATION
}

\section{Prevalent sequences in the human genome can form mini i-motif structures at physiological pH.}

\author{
Bartomeu Mir $^{\ddagger, \S}$, Israel Serrano ${ }^{\dagger}$, Diana Buitrago ${ }^{\&}$, Modesto Orozco ${ }^{\&, \%}$, Núria Escaja ${ }^{\ddagger} \S_{*}$ and Carlos \\ González $^{\dagger, \S *}$. \\ 'Instituto de Química Física 'Rocasolano', CSIC, Serrano 119, 28006 Madrid, Spain \\ ${ }^{\ddagger}$ Inorganic and Organic Chemistry Department, Organic Chemistry Section, and IBUB, University of Barcelona, Martí i \\ Franquès 1-11, 08028 Barcelona, Spain \\ ${ }^{\&}$ Institute for Research in Biomedicine (IRB), 08028 Barcelona, Spain \\ ${ }^{\%}$ Departament de Bioquímica I Biomedicina. Facultat de Biología. Universitat de Barcelona, 08028, Barcelona, Spain \\ $\S$ BIOESTRAN associated unit UB-CSIC.
}

\section{Supplementary Figures}

Figure S1: Possible folding patterns of LL3

Figure S2: Melting experiments (NMR and CD) of LL(1-3) and proposed structural model S-4

Figure S3: Melting experiments (NMR and CD) of LL(4-7) and proposed structural model S-5

Figure S4: UV melting curves of LL3 and LL4 at different $\mathrm{pH} \quad S-5$

Figure S5: NMR spectra and melting curves of LL3 and LL4 at different oligonucleotide concentration S-6

Figure S6: Native PAGE of LL(1-7) sequences $\quad$ S-6

Figure S7: H5-H6 TOCSY region of LL4-M1, LL4-M2, LL4 and LL3 S-6

Figure S8: Exchangeable protons region of NOESY spectrum of LL4-M1

Figure S9: Non-exchangeable protons region of NOESY spectrum of LL4-M1 S-8

Figure S10: Exchangeable protons region of NOESY spectrum of LL4-M2 S-9

Figure S11: Exchangeable protons region of NOESY spectrum of LL4 S-10

Figure S12: Non-exchangeable protons region of NOESY spectrum of LL3 S-11

Figure S13: Solution structure of LL3 $\quad$ S-12

$\begin{array}{ll}\text { Figure S14: NMR melting curves of MM4 and NN4 at pH } 7 & \text { S-12 }\end{array}$

Figure S15: UV and NMR melting curves of LL3rep and LL3long S-13

Figure S16: Annotation of regions with the consensus motif using GREAT Tool S-13

\section{Supplementary Tables}

Table S1: Dose-response fitting values of CD-monitored pH titration for LL3, LL4, LL3long and LL3rep S-14

Table S2: Chemical shifts of LL4-M1, $\mathrm{pH} \mathrm{7,} \mathrm{T=5^{ \circ } \mathrm { C }}$ S-14

Table S3: Chemical shifts of LL4-M2, $\mathrm{pH} 7, \mathrm{~T}=5^{\circ} \mathrm{C} \quad \mathrm{S}-14$

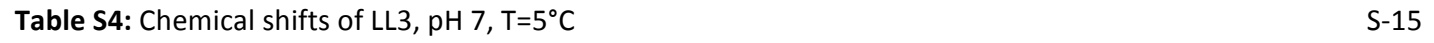

Table S5: Chemical shifts of LL4, $\mathrm{pH} \mathrm{7,T=5^{ \circ } \mathrm { C }}$ S-15

Table S6: Experimental constraints and calculation statistics of LL3 S-16

Table S7: Average dihedral angles and order parameters of the dimeric structure of LL3 S-17

$\begin{array}{ll}\text { Table S8: Genomic annotation of hits } & \text { S-17 }\end{array}$

Table S9: GO Enrichment analysis $\quad$ S-18

$\begin{array}{ll}\text { Table S10: Synthesis results for LL3 and LL4 S-18 } & \text { S }\end{array}$

$\begin{array}{ll}\text { References } & \text { S-18 }\end{array}$ 


\section{Methods}

Oligonucleotides synthesis. Oligodeoxynucleotides LL3 and LL4 were synthesized on an ABI 3400 DNA synthesizer by using standard solid-phase phosphoramidite chemistry at $1 \mu \mathrm{mol}$ scale. Cleavage from the solid support and nucleobases deprotection were carried out with concentrated aqueous ammonium hydroxide at room temperature for $12 \mathrm{~h}$. Crude products were purified by reverse phase HPLC (250x10 mm Jupiter C18 column from Phenomenex, solvent A: 0.1M TEAA $\mathrm{pH}=7$, solvent $\mathrm{B}$ : ACN). Oligonucleotides were further desalted by EtOH precipitation and characterized by MS-MALDI-TOF. Synthesis results are summarized in Supplementary Table S10. The other oligonucleotides were purchased (IDT).

Mass spectrometry. MS-MALDI-TOF spectra of LL3 and LL4 were acquired in the negative ion mode on an ABSciex 4800 plus device. Samples were prepared by mixing $1 \mu \mathrm{L}$ of oligonucleotide solution (100-500 $\mu \mathrm{M})$ with $1 \mu \mathrm{L}$ of ammonium citrate $(50 \mathrm{mg} / \mathrm{mL})$ and allowed to interact for few seconds. Next $1 \mu \mathrm{L}$ of the mixture and $1 \mu \mathrm{L}$ of the matrix $(2,4,6$ trihidroxyacetophenone, THAP, $10 \mathrm{mg} / \mathrm{mL}$ in $\mathrm{H} 2 \mathrm{O} / \mathrm{ACN}$ 1:1) were mixed and deposited onto the plate.

CD and UV spectroscopy. Circular dichroism spectra were recorded on a Jasco J-815 spectropolarimeter. UV spectra were recorded on a Jasco V-730 spectrophotometer. Both fitted with a thermostated cell holder. Spectra were recorded in 25 $\mathrm{mM}$ sodium cacodylate buffer or $25 \mathrm{mM}$ sodium acetate buffer at different $\mathrm{pH}$ values. Samples were initially heated at $90^{\circ} \mathrm{C}$ for $5 \mathrm{~min}$, and slowly allowed to cool to room temperature and stored at $4^{\circ} \mathrm{C}$ until use. $\mathrm{CD}$ and UV melting curves were recorded at the wavelength of the larger positive band, $\sim 265 \mathrm{~nm}$, with a heating rate of $0.5^{\circ} \mathrm{C} \cdot \mathrm{min}^{-1}$. Associated error in $\mathrm{T}_{\mathrm{m}}$ values determination has been estimated in $0.2^{\circ} \mathrm{C}$.

For $\mathrm{pH}$ titration experiments, the $\mathrm{pH}$ was adjusted by adding aliquots of concentrated solutions of $\mathrm{HCl}$ or $\mathrm{NaOH}$. The effective $\mathrm{pH}$-transition midpoint $\left(\mathrm{pH}_{\mathrm{T}}\right)$ values were obtained from the plot of observed ellipticity (mdeg), at around $265 \mathrm{~nm}$, versus $\mathrm{pH}$ in $25 \mathrm{mM} \mathrm{NaPi}$ buffer at $5^{\circ} \mathrm{C}$. CD versus $\mathrm{pH}$ data were fit to a standard titration model involving a single protonation event using a dose-response equation (OriginPro 8):

$$
\varepsilon=\varepsilon_{\text {unfolded }}+\frac{\varepsilon_{\text {folded }}-\varepsilon_{\text {unfolded }}}{1+10^{\text {cooperativity }\left(p H-p H_{T}\right)}}
$$

This equation allows obtaining the $\mathrm{pH}_{\mathrm{T}}$ and the cooperativity parameter (See Table S1). Associated error in $\mathrm{pH}_{\mathrm{T}}$ determination has been estimated in $0.1 \mathrm{pH}$ units.

Molar extinction coefficients for all sequences (see Supplementary Table S10) were calculated by applying the nearestneighbor method.

Gel electrophoresis. Polyacrylamide gel electrophoresis under native conditions was performed to confirm the molecularity of the structures. $20 \%$ polyacrylamide gels (acrylamide/bisacrylamide 19:1) were prepared at $\mathrm{pH} 7$ using phosphate buffer.

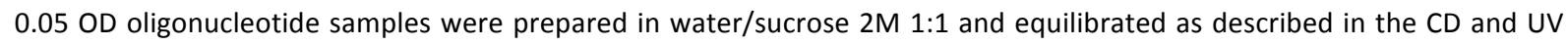
section. Running of the gels was done in phosphate buffer $50 \mathrm{mM}$ at $\mathrm{pH} 7$ for $6-7 \mathrm{~h}$ at $180 \mathrm{~V}$. Visualization of the gels was achieved by treatment with Stains-All dye from Sigma. Poly-dT references $\left(\mathrm{dT}_{20}, \mathrm{dT}_{25}, \mathrm{dT}_{30}, \mathrm{dT}_{35}, \mathrm{dT}_{40}\right.$ and $\left.\mathrm{dT}_{50}\right)$ were used as oligonucleotide length controls.

NMR. Samples for NMR experiments were dissolved (in $\mathrm{Na}^{+}$form) in either $\mathrm{D}_{2} \mathrm{O}$ or $9: 1 \mathrm{H}_{2} \mathrm{O} / \mathrm{D}_{2} \mathrm{O}, 10 \mathrm{mM}$ sodium phosphate buffer. Experiments were carried out at different $\mathrm{pH}$ values, ranging from 4 to 7 . The $\mathrm{pH}$ was adjusted by adding aliquots of concentrated solution of either $\mathrm{DCl}$ or $\mathrm{NaOD}$. All NMR spectra were acquired on Bruker spectrometers operating at 600 and $800 \mathrm{MHz}$, equipped with cryoprobes and processed with the TOPSPIN software. For the experiments in $D_{2} \mathrm{O}$, presaturation was used to suppress the residual $\mathrm{H}_{2} \mathrm{O}$ signal. A jump-and-return pulse sequence ${ }^{1}$ was employed to observe the rapidly exchanging protons in $1 \mathrm{D} \mathrm{H}_{2} \mathrm{O}$ experiments. NOESY ${ }^{2}$ spectra in $\mathrm{D}_{2} \mathrm{O}$ and 9:1 $\mathrm{H}_{2} \mathrm{O} / \mathrm{D}_{2} \mathrm{O}$ were acquired with mixing times of 150, 250 and $300 \mathrm{~ms}$. TOCSY spectra were recorded with the standard MLEV-17 spin-lock sequence and a mixing time of 80 ms. In most of the experiments in $\mathrm{H}_{2} \mathrm{O}$, water suppression was achieved by including a WATERGATE ${ }^{4}$ module in the pulse sequence prior to acquisition. The spectral analysis program SPARKY was used for semiautomatic assignment of the NOESY cross-peaks and quantitative evaluation of the NOE intensities.

Assignment of the NMR spectra. The NMR spectra of all sequences exhibit very similar features, although we focused on LL3 and LL4. To overcome the intrinsic difficulties of the specific assignment of repetitive sequences, we studied two additional oligonucleotides in which one or two cytosines were replaced by 5 -methyl-cytosine residues $\left({ }^{m} C\right)$. The NMR spectra of these two oligonucleotides LL4-M1: d(T ${ }^{\mathrm{m}}$ CGTTCCGT-T4-TCGTTCCGT); and LL4-M2: d(T ${ }^{\mathrm{m}}$ CGTTCCGT-T4- 
$\mathrm{T}^{\mathrm{m}}$ CGTTCCGT) were partially assigned. Unambiguous assignment of $\mathrm{C} 2$ and $\mathrm{C} 15$ residues in LL4 could be carried out by observing the changes in the H5-H6 region of the TOCSY spectra (Figure S7). From these starting points, sequential assignment of all the residues could be carried out by analyzing TOCSY and NOESY spectra following standard methods. Assignment details for LL4-M1 are given in Figures S8 and S9, for LL4-M2 in Figure S10, LL4 in Figure S11, and for LL3 in Figure S12. In these figures, cross-peaks involving multiple overlapped resonances are labelled using a slash symbol (i.e. $\left.\mathrm{H}^{\prime} \mathrm{C} 7 / \mathrm{C} 20-\mathrm{H} 8 \mathrm{G} 8 / \mathrm{G} 21\right)$. Chemical shift lists are given in Tables S2-5.

NMR constraints. Qualitative distance constraints were obtained from NOE intensities. NOEs were classified as strong, medium or weak, and distances constraints were set accordingly to 3,4 or $5 \AA \AA$. In addition to these experimentally derived constraints, hydrogen bond and planarity constrains for the base pairs were used. Target values for distances and angles related to hydrogen bonds were set to values obtained from crystallographic data in related structures ${ }^{5}$. Due to the relatively broad line-widths of the sugar proton signals, J-coupling constants were not accurately measured, but only, roughly estimated from DQF-COSY cross-peaks. Loose values were set for the sugar dihedral angles $\delta, v_{1}$ and $v_{2}$ to constrain deoxyribose conformation to North or South domain.

Structural calculations. Structures were calculated with the program DYANA ${ }^{6}$ and further refined with the SANDER module of the molecular dynamics package AMBER $12.0^{7}$. Resulting DYANA structures were taken as starting points for the AMBER refinement, consisting of an annealing protocol in vacuo, followed by trajectories of 500 ps each in which explicit solvent molecules were included and using the Particle Mesh Ewald method to evaluate long-range electrostatic interactions. The specific protocols for these calculations have been described elsewhere ${ }^{8}$. The BSC1 force field ${ }^{9}$ was used to describe the DNA, and the TIP3P model was used to simulate water molecules. Analysis of the representative structures was carried out with the program MOLMOL ${ }^{10}$.

The structural models for the sequences with different poly-thymine loops shown in Figures S2 and S3 were built on the basis of their similar spectra to LL3. The experimental distances observed for LL3 were renumbered according to the different sequences and the models were calculated with the program DYANA. No refinement with AMBER package was carried out in this case. 


\section{Supplementary Figures}
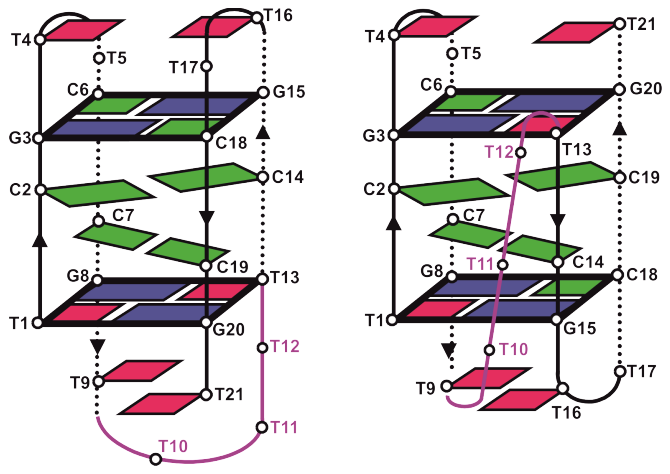

Figure S1. Possible unimolecular folding patterns for LL3 are shown. In the head-to-head like structure one G:C:G:C and one G:C:G:T tetrads are formed, whereas in the head-to-tail like structure two mixed G:C:G:T tetrads are formed. Moreover, the pattern of $\mathrm{C}: \mathrm{C}^{+}$base-pairs differs in each of the two arrangements. In the head-to-head like orientation (left), C2:C14 and $\mathrm{C7:C19}$ base pairs are expected, whereas in the head-to-tail one (right), the base pairs should be $\mathrm{C2:C19}$ and C7:C14. The assignment of the exchangeable protons spectra of LL3 and LL4 (see Figures 2 and S11) clearly shows the formation of the latter structure. Colour code: $\mathrm{C}$ in green, $\mathrm{G}$ in blue, and $\mathrm{T}$ in magenta

LL1
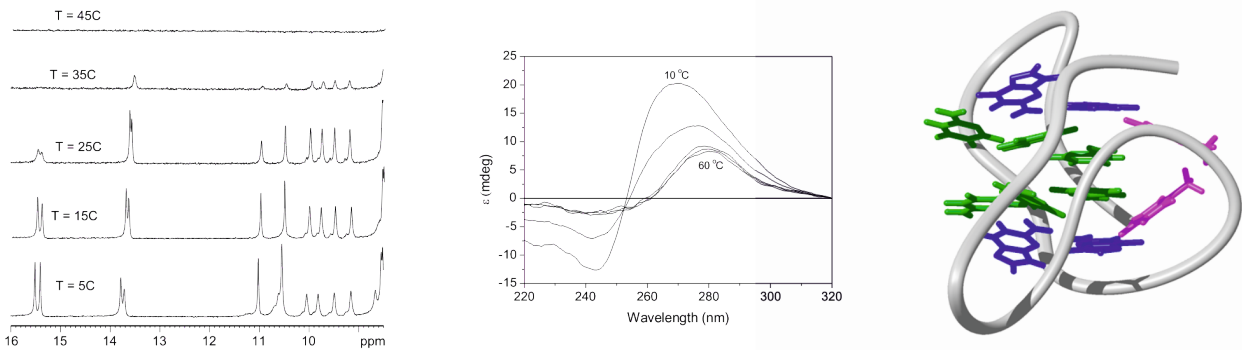

LL2
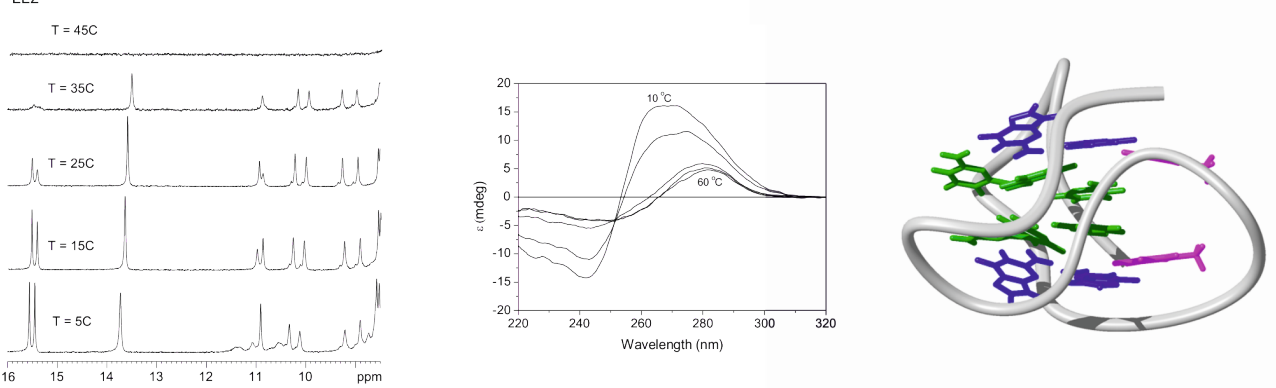

LL3
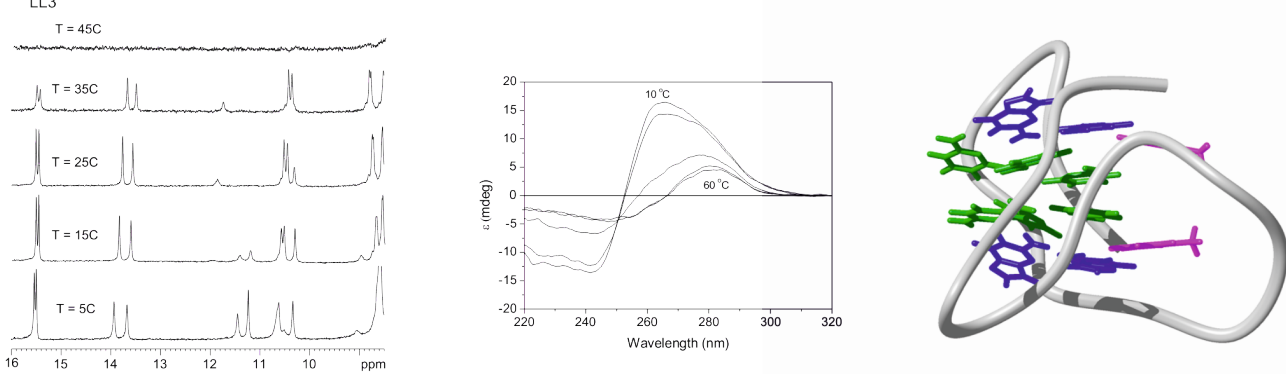

Figure S2. NMR and CD melting experiments at $\mathrm{pH} 7$ (phosphate buffer, [oligonucleotide] $=1 \mathrm{mM}$ for NMR and $3.5 \mu \mathrm{M}$ for CD) and structural models of LL1, LL2 and LL3. Only the nucleotides forming the C: $\mathrm{C}^{+}$and G:C:G:T tetrads are shown. Colour code: cytosine in green, guanines in blue, and thymine in magenta. 

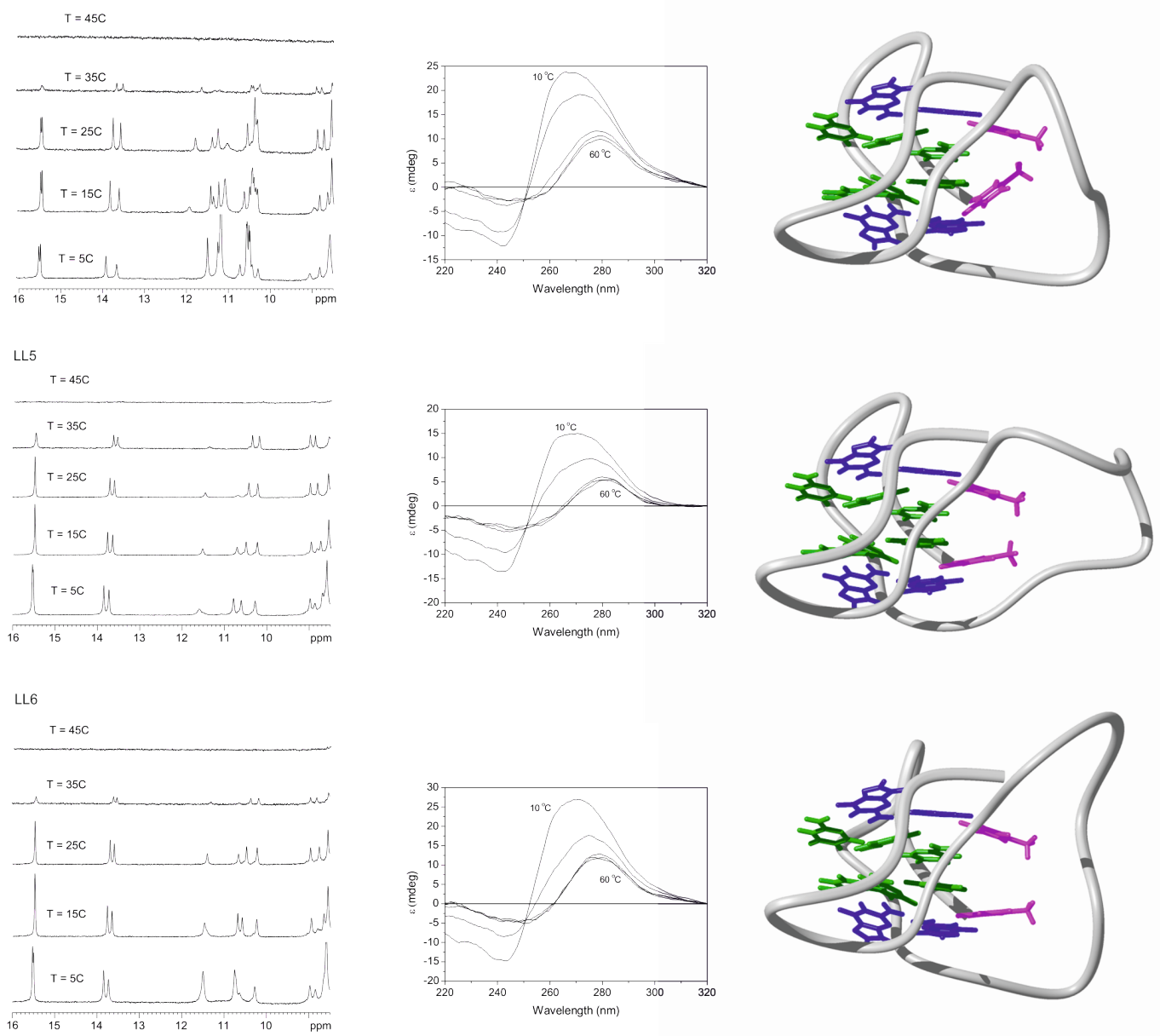

LL7
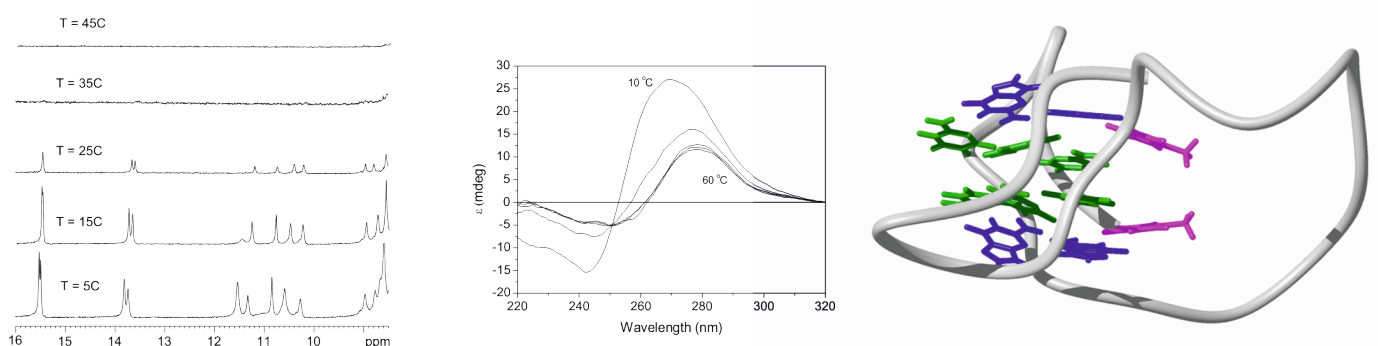

Figure S3. NMR and CD melting experiments at $\mathrm{pH} 7$ (phosphate buffer, [oligonucleotide]=1 mM for NMR and $3.5 \mu \mathrm{M}$ for CD) and and structural models of LL4, LL5, LLA6 and LL7. Only the nucleotides forming the C:C ${ }^{+}$and G:C:G:T tetrads are shown. Colour code: cytosine in green, guanines in blue, and thymine in magenta.
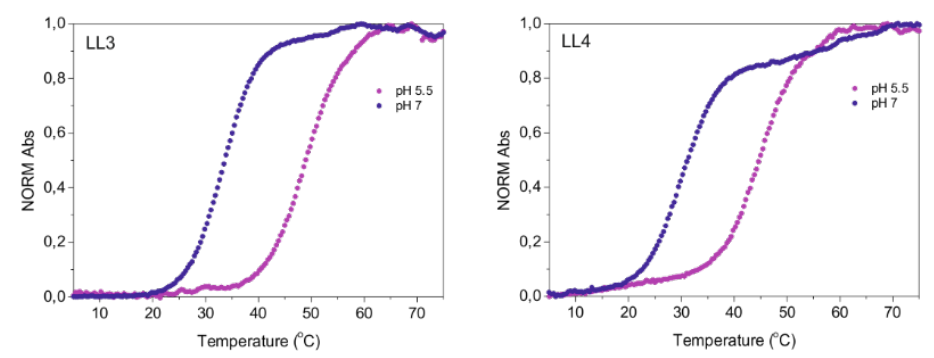

Figure S4. UV melting curves of LL3 and LL4 at different $\mathrm{pH}$. [oligonucleotide] $=3,5 \mu \mathrm{M}, 25 \mathrm{mM}$ cacodylate buffer. 

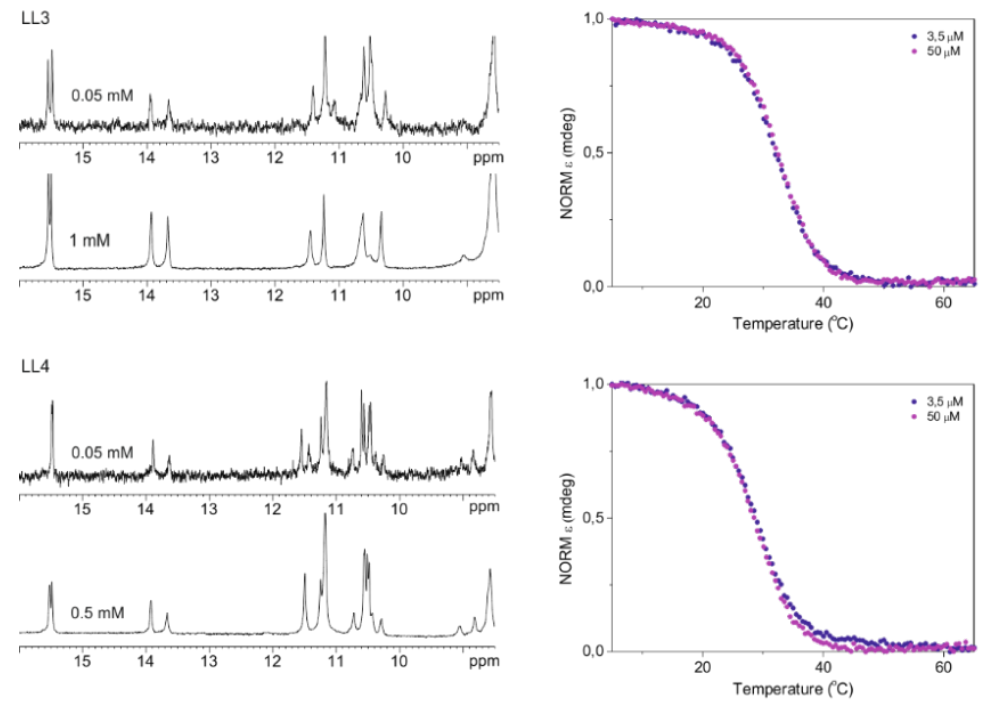

Figure S5. Left: NMR spectra of LL3 and LL4 at different oligonucleotide concentration, phosphate buffer $\mathrm{pH} 7, \mathrm{~T}=5^{\circ} \mathrm{C}$. Right: CD melting curves of LL3 and LL4 at different oligonucleotide concentration, phosphate buffer, $\mathrm{pH} 7$.

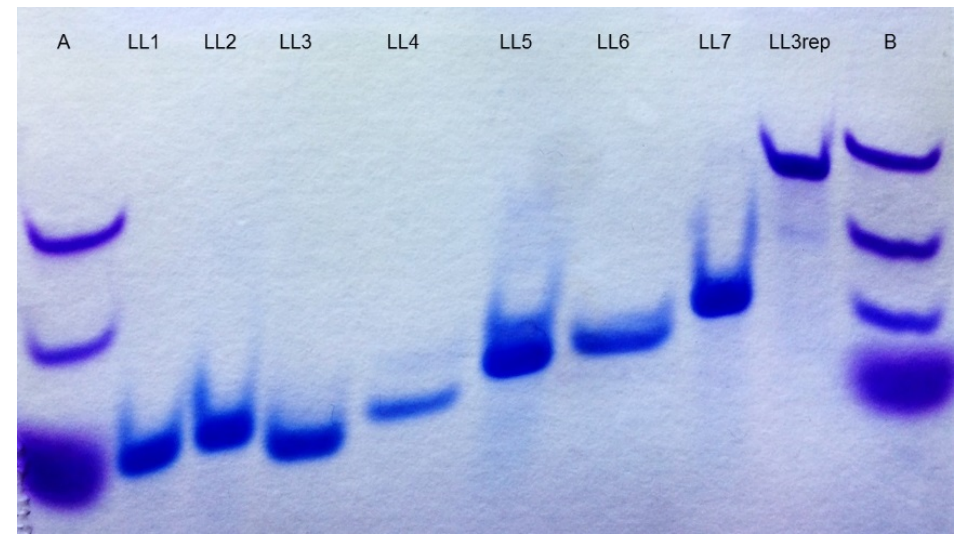

Figure S6. Native PAGE of LL sequences. 20\% polyacrylamide gels (acrylamide/bisacrylamide 19:1), pH 7, phosphate buffer $0.05 \mathrm{M}$. Experimental conditions: $180 \mathrm{~V}$ for 6-7 hours, $T=5^{\circ} \mathrm{C} . \mathrm{A}=\mathrm{dT}_{15}, \mathrm{dT}_{25}, \mathrm{dT}_{40}+$ bromophenol. $\mathrm{B}=\mathrm{dT}_{20}, \mathrm{dT}_{30}, \mathrm{dT}_{50}+$ bromophenol.

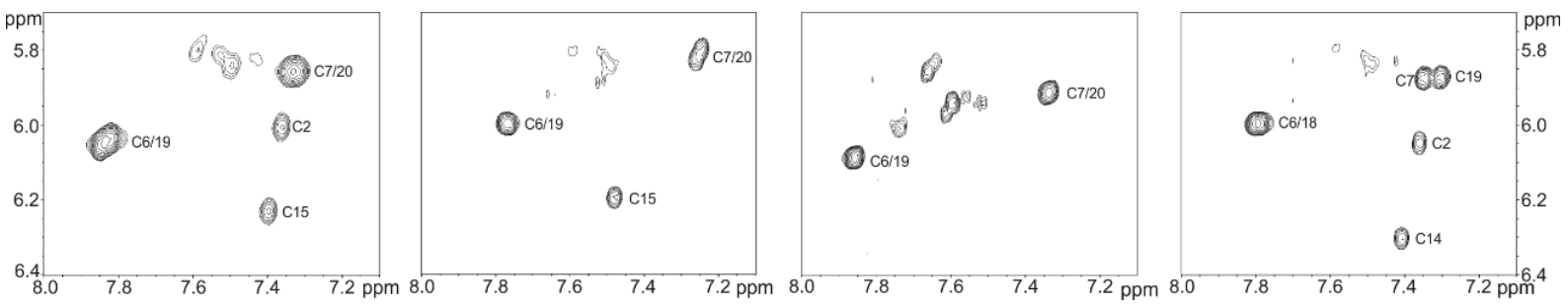

Figure S7. From left to right, H5-H6 cross-peaks region of TOCSY spectra of LL4, LL4-M1, LL4-M2 and LL3. Comparison of H5H6 cross-peaks region of the TOCSY spectra of LL4 with two analogue sequences, LL4-M1 and LL4-M2, in which a single cytosine in position 2, or two cytosines in positions 2 and 15, have been replaced by 5-methyl-cytosines. Unambiguous assignment of $\mathrm{C} 2$ and $\mathrm{C} 15$ residues was carried out by observing the H5-H6 cross-peaks that disappear in LL4-M1 (C2) and in LL4-M2 (C2 and C15). Chemical shifts of H5/H6 protons of $\mathrm{C} 6 / \mathrm{C} 19$ and $\mathrm{C} 7 / \mathrm{C} 20$ do not change significantly in any case upon 5-methyl-cytosine substitution. 


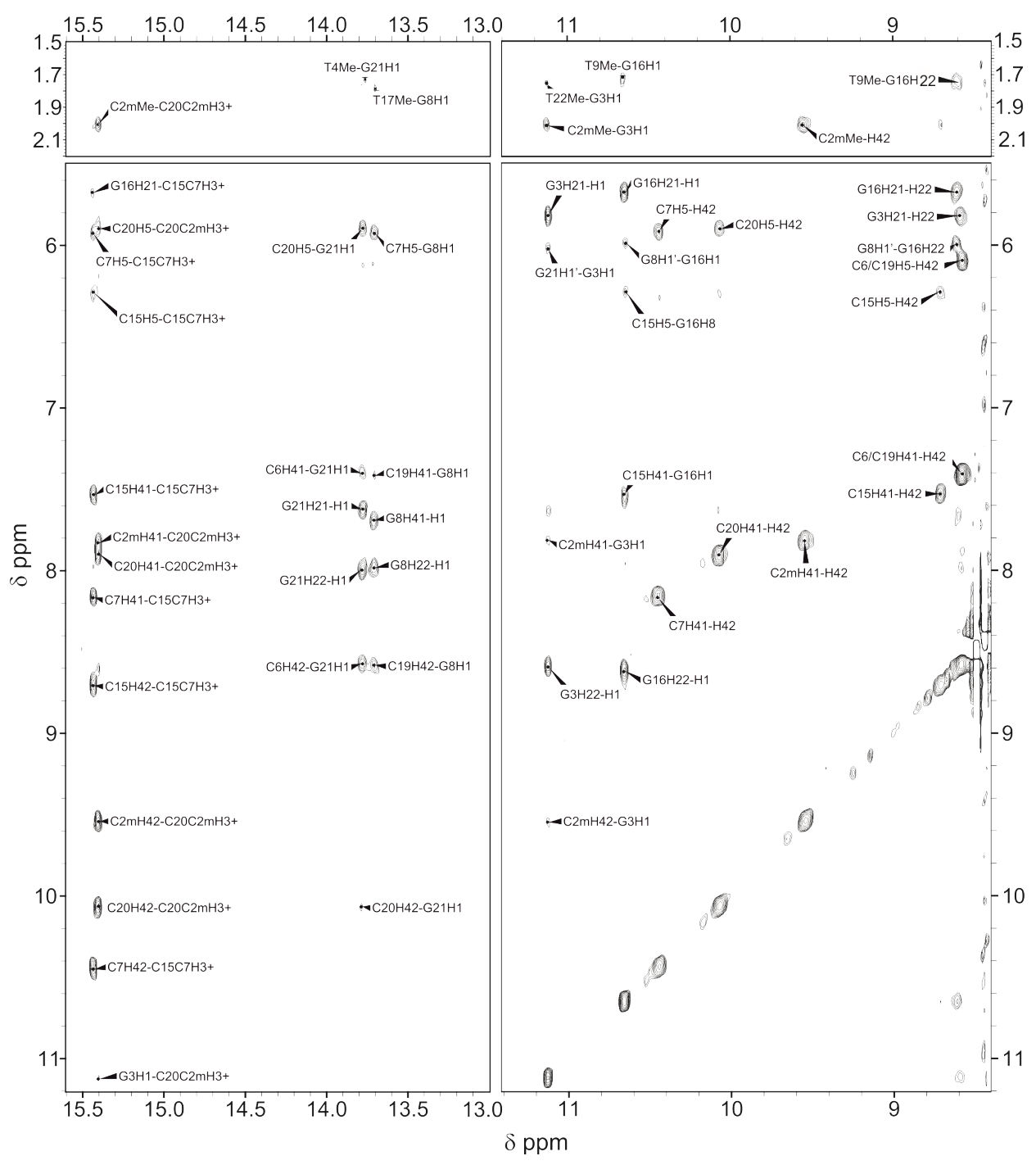

Figure S8. Exchangeable protons regions of NOESY spectrum (150 ms) of LL4-M1, phosphate buffer $\mathrm{pH} 7, \mathrm{~T}=5^{\circ} \mathrm{C}$, [oligonucleotide]=1 $\mathrm{mM}$.

Assignment details of exchangeable protons region of LL4-M1: As shown in Figure S8, LL4-M1 exhibits two signals in the characteristic region of hemiprotonated $\mathrm{C}: \mathrm{C}^{+}$base pairs $(15.44$ and $15.41 \mathrm{ppm}$ ) that show cross-peaks with two pairs of amino protons, consistent with the formation of $\mathrm{C}: \mathrm{C}^{+}$pairs between non-equivalent cytosines. Two additional imino signals in the G:C WC base pairs region are also observed at 13.77 and $13.71 \mathrm{ppm}$. Starting from methylated ${ }^{\mathrm{m}} \mathrm{C} 2$ residue (labelled as $\mathrm{C} 2 \mathrm{~m}$ in the spectrum), the other cytosine residues involved in $\mathrm{C}: \mathrm{C}^{+}$base pairs could be unambiguously assigned: ${ }^{\mathrm{m}} \mathrm{C} 2$ is hydrogen bonded to $\mathrm{C} 15$ and the other $\mathrm{C}: \mathrm{C}^{+}$base pair is formed between $\mathrm{C} 7$ and $\mathrm{C} 20 . \mathrm{C} 6$ and $\mathrm{C} 19$, that show degenerated signals, are involved in G:C WC base pairs formation (C6:G21 and C19:G8) and expected H1G21-H41/H42C6 and H1G8$\mathrm{H} 41 / \mathrm{H} 42 \mathrm{C} 19$ cross-peaks are observed. Formation of mixed tetrads is also supported by the significant differences found in the chemical shift of the amino protons of paired hemiprotonated cytosines. Amino protons of cytosines capped by the $\mathrm{G}: \mathrm{C}$ base pair of the tetrad are significantly downshifted than those capped by the G:T base pair. Some cross-peaks also support the minor groove interaction between guanine residues: $\mathrm{H} 1^{\prime} \mathrm{G} 8-\mathrm{H} 1 / \mathrm{H} 22 \mathrm{G} 16$ and $\mathrm{H} 1^{\prime} \mathrm{G} 21 / \mathrm{H} 1 \mathrm{G} 3$. Stacking contacts between guanine residues and hemiprotonated $\mathrm{C}: \mathrm{C}^{+}$pairs are also observed: $\mathrm{H} 5 \mathrm{C} 7-\mathrm{H} 1 / \mathrm{H} 21 / \mathrm{H} 22 \mathrm{G} 8$ and H5/H42C21-H1G21. 


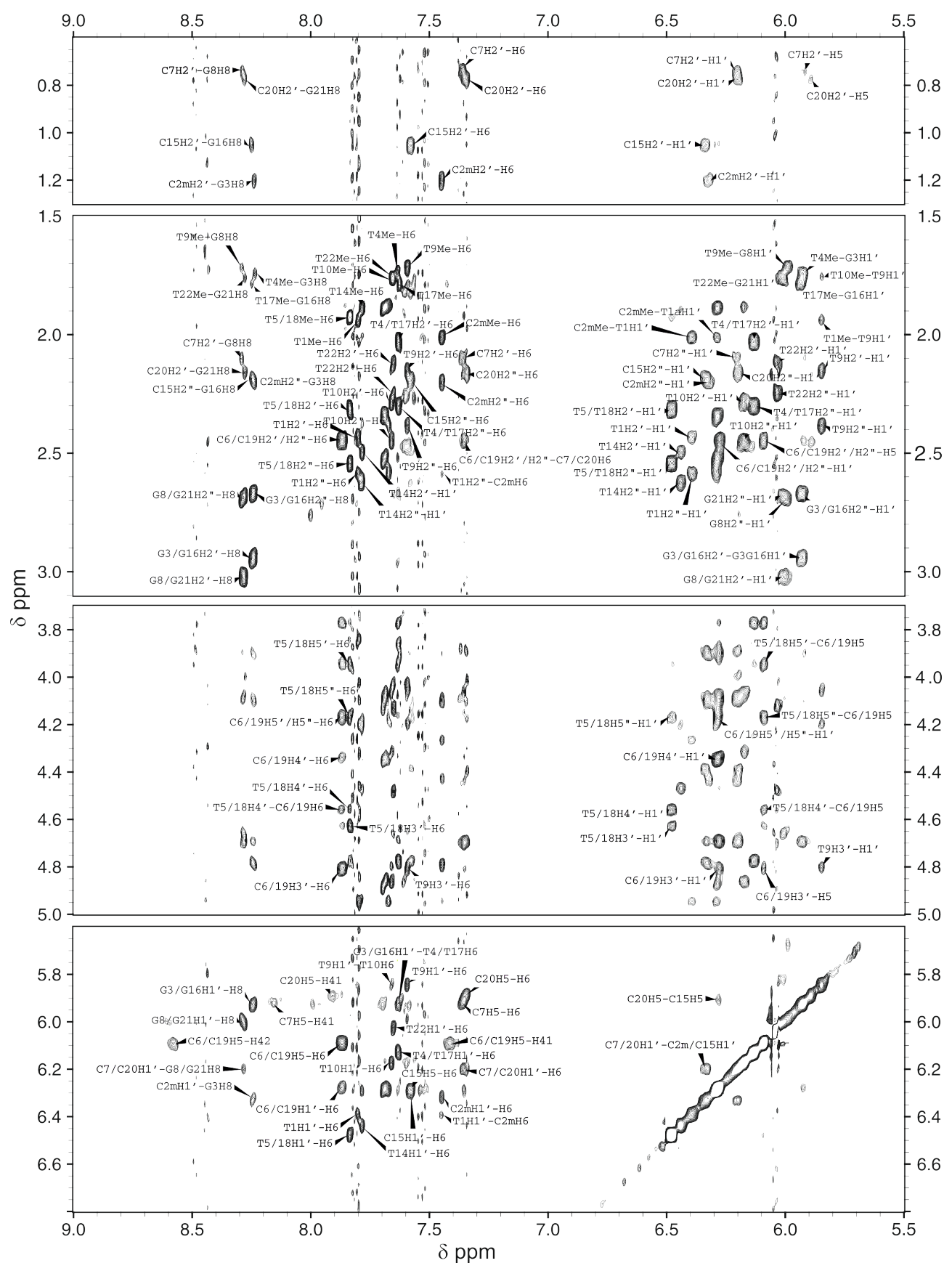

Figure 59. Non-exchangeable protons regions ( $\mathrm{Ar}-\mathrm{H} 1^{\prime} / \mathrm{H} 5$ and $\mathrm{Ar}-\mathrm{H} 2^{\prime} / \mathrm{H} 2^{\prime \prime} / \mathrm{Me}$ ) of NOESY spectrum (150 ms) of LL4-M1, phosphate buffer $\mathrm{pH} 7, \mathrm{~T}=5^{\circ} \mathrm{C}$, [oligonucleotide] $=1 \mathrm{mM}$. Cross-peaks involving multiple overlapped resonances are labelled with a slash symbol.

Assignment details of non-exchangeable protons of LL4-M1: As shown in Figure S9, LL4-M1 is completely structured at pH 7 and low temperature $\left(\mathrm{T}=5^{\circ} \mathrm{C}\right)$. A large number of sequential cross-peaks are observed: $\mathrm{Me}^{\mathrm{m}} \mathrm{C} 2-\mathrm{H} 1^{\prime} \mathrm{T} 1, \mathrm{H} 2^{\prime \prime} / \mathrm{H} 1^{\prime} \mathrm{T} 1-\mathrm{H} 6^{\mathrm{m}} \mathrm{C} 2$, $\mathrm{H} 1^{\prime} / \mathrm{H}^{\prime} / \mathrm{H} 2^{\prime \prime} \mathrm{m} C 2-\mathrm{H} 8 \mathrm{G} 3, \mathrm{MeT4}-\mathrm{H} 1^{\prime} \mathrm{G} 3, \mathrm{MeT} 9-\mathrm{H} 8 \mathrm{G} 8, \mathrm{H} 2^{\prime} / \mathrm{H} 2^{\prime \prime C} 6 / \mathrm{C} 19-\mathrm{H} 6 \mathrm{C} 7 / \mathrm{C} 20, \mathrm{H} 2^{\prime} / \mathrm{H} 2^{\prime \prime C} 7-\mathrm{H} 8 \mathrm{G} 8, \mathrm{H} 1^{\prime} \mathrm{C} 7 / \mathrm{C} 20-\mathrm{H} 8 \mathrm{G} 8 / \mathrm{G} 21$, $\mathrm{H}^{\prime} / \mathrm{H} 2^{\prime \prime} \mathrm{C} 15-\mathrm{H} 8 \mathrm{G} 16, \mathrm{H} 2^{\prime} / \mathrm{H} 2^{\prime \prime} \mathrm{C} 20-\mathrm{H} 8 \mathrm{G} 21, \mathrm{MeT17}-\mathrm{H} 1^{\prime} \mathrm{G} 16, \mathrm{MeT22}-\mathrm{H} 1^{\prime} \mathrm{G} 21$. Residues located in the core of the structure showed characteristic $\mathrm{H}^{\prime} \mathrm{C} 7 / 20-\mathrm{H} 1^{\prime m} \mathrm{C} 2 / \mathrm{C} 15$ cross-peaks across the minor groove and stacking contacts $\mathrm{H} 5 \mathrm{C} 20-\mathrm{H} 5 \mathrm{C} 15$. T5 and T18 residues are degenerated. These residues are exposed to the solvent, but they could be assigned on the basis of sequential sugar contacts: $\mathrm{H}^{\prime} / \mathrm{H}^{\prime} / \mathrm{H} 5^{\prime \prime} \mathrm{T} 5 / \mathrm{T} 18-\mathrm{H} 5 / \mathrm{H} 6 \mathrm{C} 6 / \mathrm{C} 19$. Some contacts involving thymine loop residues are observed: $\mathrm{H} 1^{\prime} \mathrm{T} 9-\mathrm{H} 6 \mathrm{~T} 10, \mathrm{MeT10}-\mathrm{H} 1^{\prime} \mathrm{T} 9$ and $\mathrm{Me}^{\mathrm{m}} \mathrm{C} 2-\mathrm{H} 1^{\prime} \mathrm{Tla}$. (Tla indicates thymine loop residue that could not be sequentially assigned) 


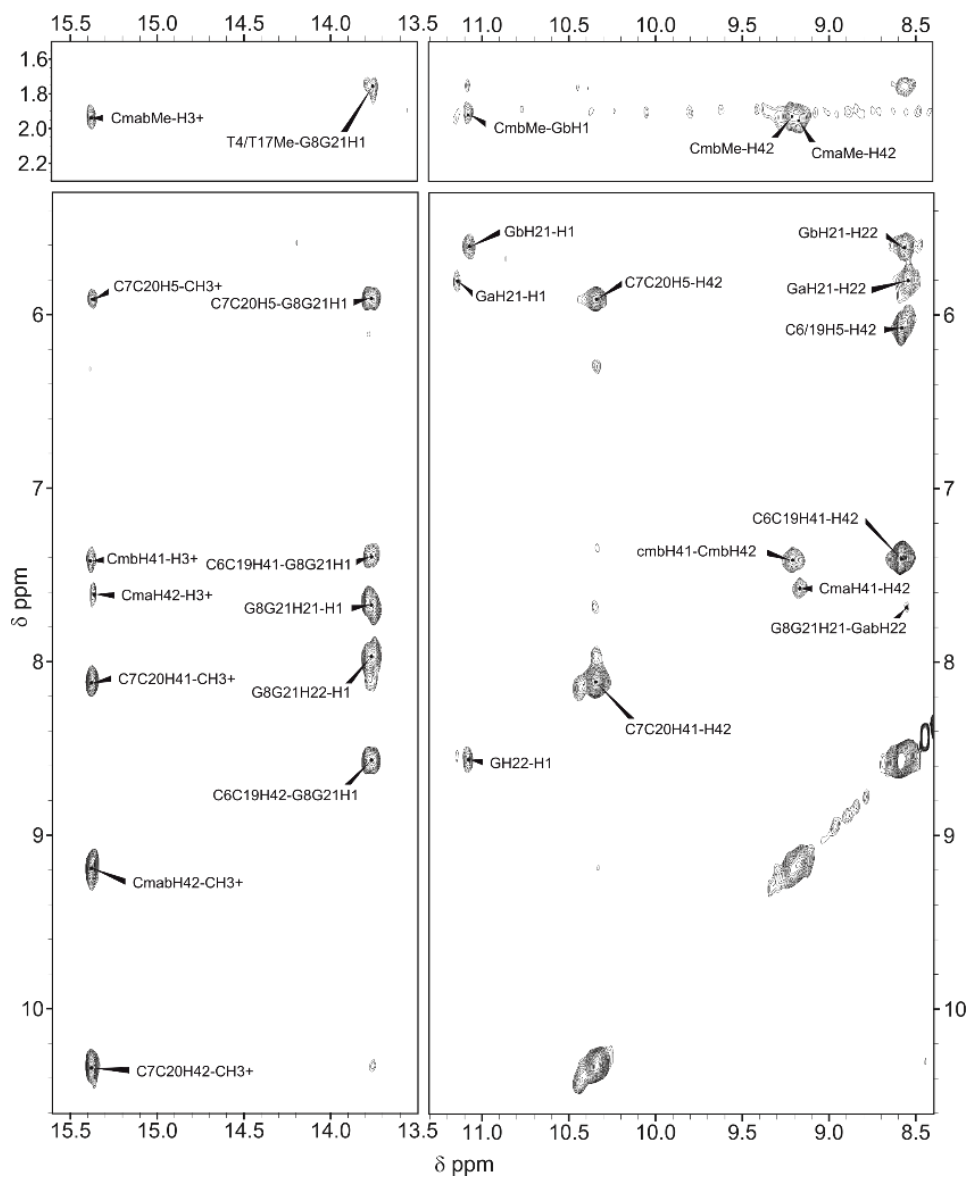

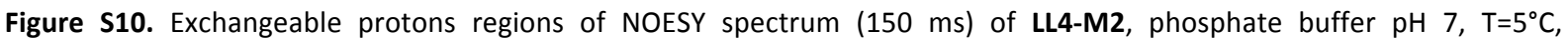
[oligonucleotide]=1 $\mathrm{mM}$. Cross-peaks involving multiple overlapped resonances are labelled with a slash symbol.

Assignment details of exchangeable protons region of LL4-M2: As can be observed in this Figure S10, only two H5/H6 cross-peaks are observed. One of them corresponds to the cytosines involved in Watson-Crick base pairs (C6/C19). The other corresponds to $\mathrm{C} 7 / \mathrm{C} 20$, involved in $\mathrm{C}: \mathrm{C}^{+}$base pairs. The observed degeneration of signals corresponding to $\mathrm{C} 7 / \mathrm{C} 20$ and $\mathrm{C} 6 / \mathrm{C} 19$ (exchangeable and non-exchangeable signals) points to a symmetric structure. The two methylated cytidines (labelled as $\mathrm{Cm}$ in the spectrum) show degenerated signals for exchangeable protons $\mathrm{H} 41 / \mathrm{H} 42$, but not for the nonexchangeable ones. One $\mathrm{C}: \mathrm{C}^{+}$imino signal is observed $(15.37 \mathrm{ppm})$, showing cross-peaks with $\mathrm{C} 7 / \mathrm{C} 20 /{ }^{\mathrm{m}} \mathrm{C} 2{ }^{\mathrm{m}} \mathrm{C} 15$ residues. It cannot be unambiguously deduced from this signal the composition of the base pairs (one $\mathrm{C}: \mathrm{C}^{+}$and one ${ }^{\mathrm{m}} \mathrm{C}:{ }^{\mathrm{m}} \mathrm{C}^{+}$or two ${ }^{\mathrm{m}} \mathrm{C}: \mathrm{C}^{+}$ base pairs), but it seems like ${ }^{\mathrm{m}} \mathrm{C} 2$ and ${ }^{\mathrm{m}} \mathrm{C} 15$ are not perfectly aligned in one $\mathrm{H}^{+}$chemical shift (15.38 and 15.36 ppm). This observation would be only consistent with the formation of ${ }^{\mathrm{m}} \mathrm{C}: \mathrm{C}^{+}$base pairs and, hence a head to tail orientation. At 13.76 $\mathrm{ppm}$, it is observed an imino proton signal that corresponds to two guanine residues (with degenerated exchangeable signals) involved in G:C WC base pairs with C6/C15. This imino signal also shows cross-peaks with amino protons of C7/C20 residues, indicating stacking interacions. At 11.15 and $11.08 \mathrm{ppm}$, two additional guanine imino signals are observed. These signals exhibit cross-peaks with their own amino protons and with the Me group of methylated cytidines ${ }^{\mathrm{m}} \mathrm{C} 2{ }^{\mathrm{m}} \mathrm{C} 15$. 


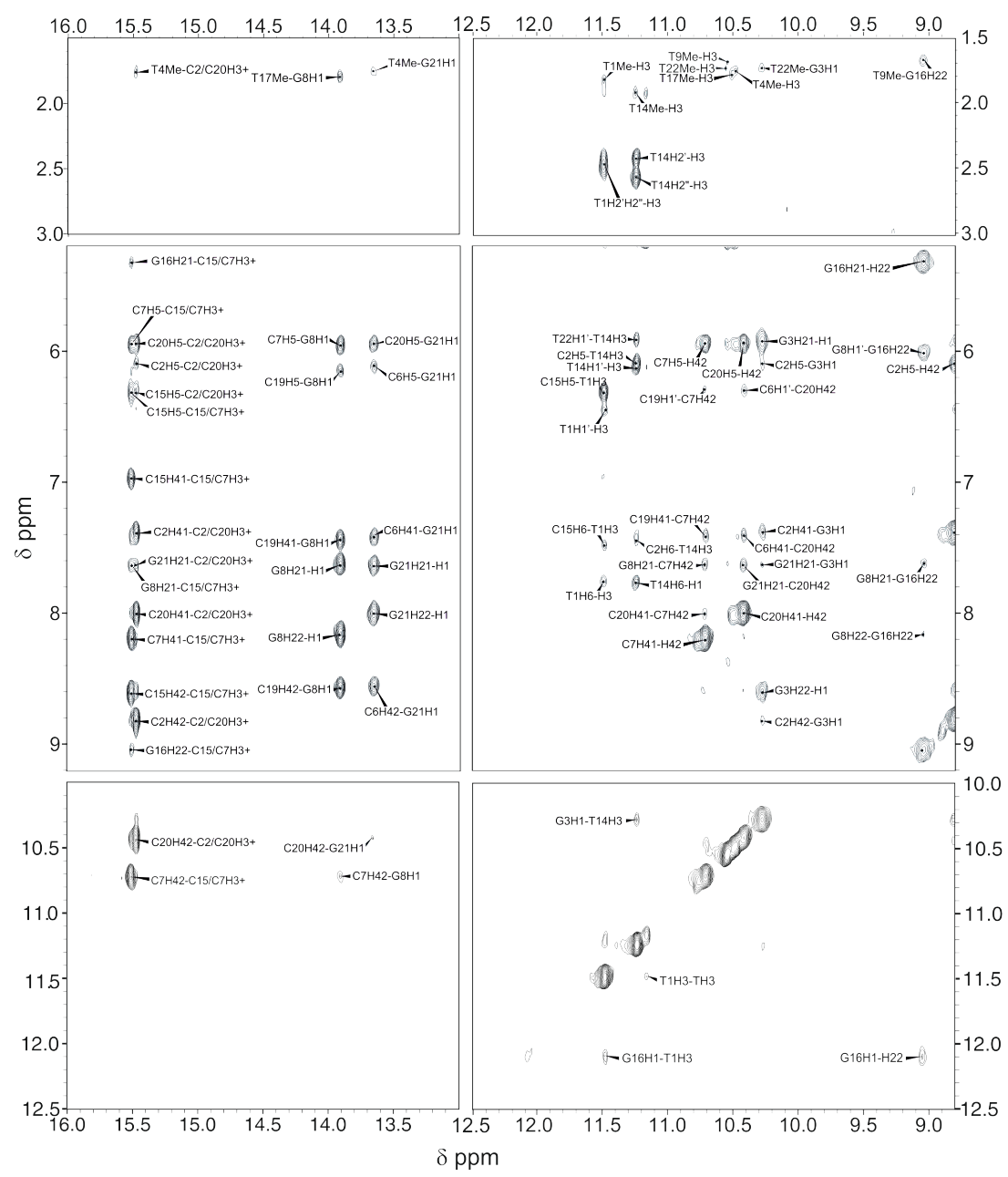

Figure S11. Exchangeable protons regions of NOESY spectrum (150 ms) of LL4, phosphate buffer $\mathrm{pH} 7, \mathrm{~T}=5^{\circ} \mathrm{C}$, [oligonucleotide]=1 mM. Cross-peaks involving multiple overlapped resonances are labelled with a slash symbol.

Assignment details of exchangeable protons region of LL4: As can be observed in Figure S11, LL4 exhibits two hemiprotonated imino signals at 15.51 and $15.48 \mathrm{ppm}$. Each of these signals show cross-peaks with two pairs of amino protons. Unequivocal assignment of $\mathrm{C} 2$ and $\mathrm{C} 15$ (see Figure S7) allowed to determine cytosine residues involved in C: $\mathrm{C}^{+}$ base pairs (C2, C7, C15 and C20). According to amino/imino cross-peaks, $\mathrm{C} 2$ and $\mathrm{C} 15$ are involved in different $\mathrm{C}: \mathrm{C}^{+}$base pairs, thus confirming that the two protonated imino signals correspond to $\mathrm{C} 2:{\mathrm{C} 20^{+}}^{+}$and $\mathrm{C} 7: \mathrm{C}_{15}{ }^{+}$base pairs. $\mathrm{C} 7$ and $\mathrm{C} 20$ amino protons are particularly unshielded (10.72 and $10.42 \mathrm{ppm}$, respectively). This base-pairing pattern is only compatible with a head-to-tail like strand folding (see Figure S1). Two different types of guanine imino protons are observed. Two guanine imino signals are found in the characteristic region of G:C WC base pairs, at 13.91 and 13.66 ppm, and show crosspeaks with amino protons of $\mathrm{C} 6$ and $\mathrm{C} 19$ (C6: G21 and C19:G8 base pairs). The other two guanine imino signals are found at $12.08 \mathrm{ppm}, \mathrm{G} 16$ (exhibiting a broader signal), and at $10.28 \mathrm{ppm}, \mathrm{G} 3$. Both signals show cross-peaks with imino protons of two thymine residues: T1 (11.49 ppm) and T14 (11.24), indicating the formation of G:T base pairs (G3:T14 and G16:T1 base pairs). The broad signal observed for G16 suggests that this guanine might be more exposed to the solvent than G3. Formation of G:C:G:T tetrads is supported by a number of cross-peaks: H1'G8-H22G16, H21/H22G8-H22G16 and the significant differences found in the chemical shift of amino protons of stacked hemiprotonated cytosines, depending on whether they are capped by the G:C or the G:T base pair of the tetrad. Thymine residues T4, T9, T17 and T22 are stacked over the tetrads and methyl groups of these thymines show cross-peaks with exchangeable and non-exchangeable protons of guanine residues: MeT22-H1/H22G3, MeT9-H22G16, MeT17-H1G8, MeT4-H1G21, MeT4-H8/H1'G3, MeT9-H8/H1'G8, MeT17-H8/H1'G16 and MeT22-H8/H1'G21. Moreover, imino signals corresponding to stacked thymine residues are also observed in the 10-12 ppm region: T4 (10.48 ppm), T17 (10.51 ppm), T9 (10.54 ppm) and T22 (10.55 ppm), indicating that these residues are solvent protected. Characteristic i-motif cross-peaks between cytidine residues across the minor groove are also observed: $\mathrm{H} 1^{\prime} \mathrm{C} 20-\mathrm{H} 1^{\prime} \mathrm{C} 15$ and $\mathrm{H} 1^{\prime} \mathrm{C} 6 / \mathrm{C} 19-\mathrm{H} 5 \mathrm{C} 20 / \mathrm{C} 7$. 
Sequential assignment based on H6/H8-H2'/H2"/H1' cross-peaks could be completed for C2-G3-T4, C6-C7-G8-T9, C15-G16T17 and C19-C20-G21-T22 fragments. Thymine residues T1 and T14 can be identified by their own intraresidual $\mathrm{Me} / \mathrm{H}^{\prime} / \mathrm{H} 2^{\prime \prime}-\mathrm{H} 3$ cross-peaks. These residues show some non-sequential cross-peaks across the major groove (H2" $11-\mathrm{H} 6 \mathrm{C} 15$ and $\mathrm{H} 2 " \mathrm{~T} 13-\mathrm{H} 6 \mathrm{C} 2)$. Stacked thymine residues (T4, T9, T17 and T22) also show very weak intraresidual Me-H3 cross-peaks.

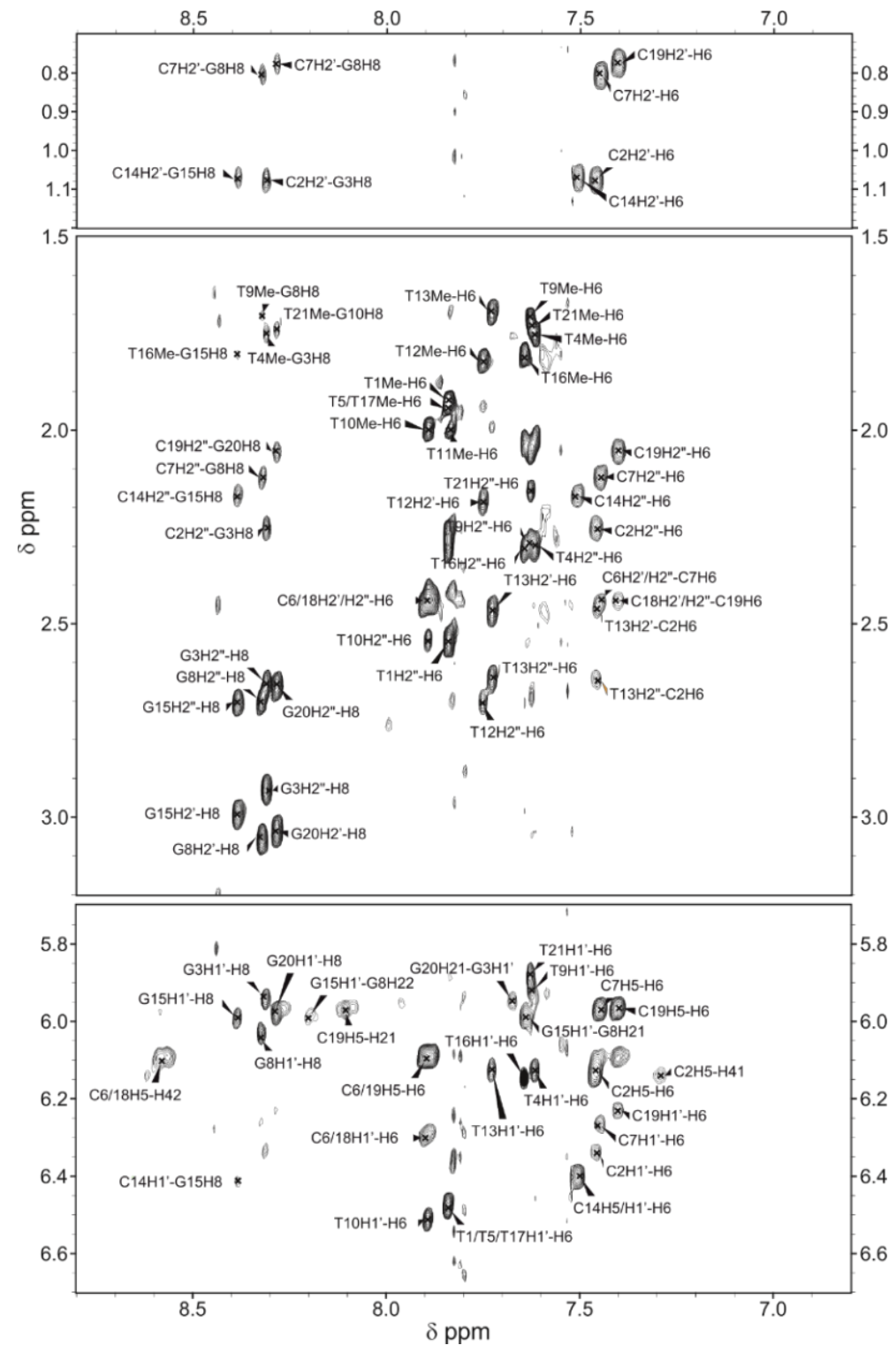

Figure S12. Non-exchangeable protons regions ( $\mathrm{Ar}-\mathrm{H} 1^{\prime} / \mathrm{H} 5$ and $\mathrm{Ar}-\mathrm{H} 2^{\prime} / \mathrm{H} 2^{\prime \prime} / \mathrm{Me}$ ) of NOESY spectrum (150 ms) of LL3, phosphate buffer $\mathrm{pH} 7, \mathrm{~T}=5^{\circ} \mathrm{C}$, [oligonucleotide] $=1 \mathrm{mM}$. Cross-peaks involving multiple overlapped resonances are labelled with a slash symbol.

Assignment details of non-exchangeable protons of LL3: Sequential assignment based on $\mathrm{H} 6 / \mathrm{H} 8-\mathrm{H} 2^{\prime} / \mathrm{H} 2^{\prime \prime} / \mathrm{H} 1^{\prime}$ cross-peaks could be completed for C2-G3-T4, C6-C7-G8-T9, C14-G15-T16 and C18-C19-G20-T21 fragments. As shown in Figure S12, thymine residues $\mathrm{T} 1$ and $\mathrm{T} 13$ can be identified by own $\mathrm{Me} / \mathrm{H}^{\prime} / \mathrm{H} 2^{\prime \prime}-\mathrm{H} 3$ cross-peaks. These residues show some nonsequential cross-peaks across the major groove (H2"T1-H6C14 and H2"T13-H6C2). Characteristic i-motif cross-peaks between cytidine residues through the minor groove are also observed: $\mathrm{H}^{\prime} \mathrm{C} 19-\mathrm{H} 1^{\prime} \mathrm{C} 14$ and $\mathrm{H} 1^{\prime} \mathrm{C} 6-\mathrm{H} 5 \mathrm{C} 19$. In addition, some thymine residues in the loop could be assigned on the basis of Me-H1' and Me-H6 cross-peaks. All NMR data is consistent with the formation of an unimolecular head-to-tail i-motif structure containing G:C:G:T minor groove tetrads. 
A
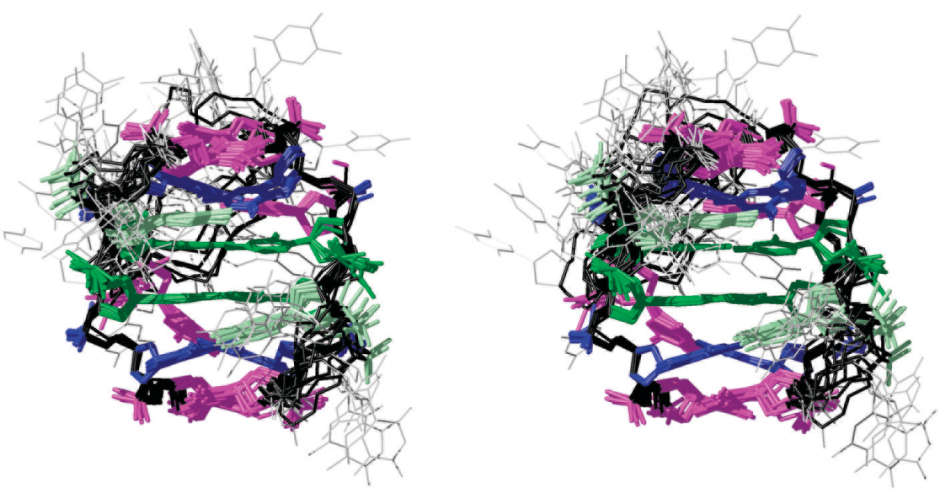

B
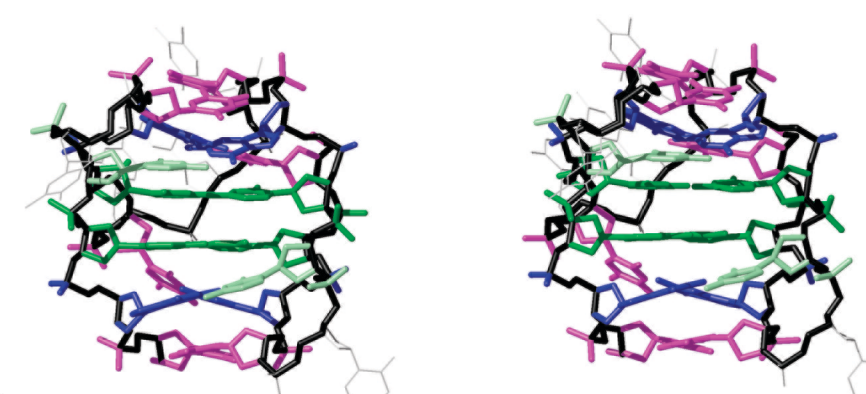

C
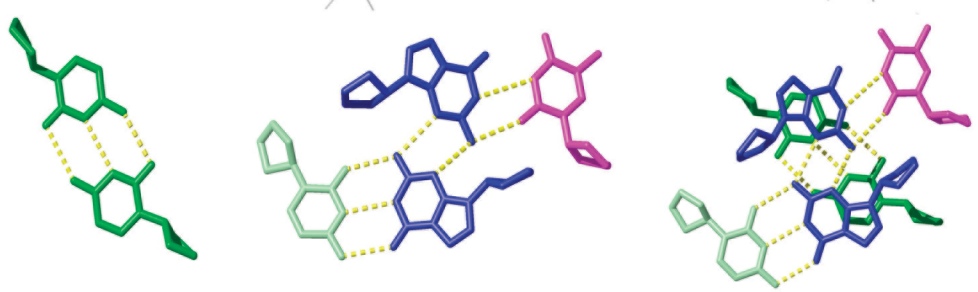

Figure S13. A) Stereoviews of the ensemble of ten structures of LL3. B) Stereoviews of the average structure. C) C: $C^{+}$base pair, G:C:G:T minor groove tetrad and stacking of thymine residues on the tetrad. Colour code: Cytosines in green, guanines in blue, and well-defined thymines in magenta. Cytosines involved in CG base pairs are shown in light green. Thymines with non well-defined structures are shown in grey. Backbone is shown in black.
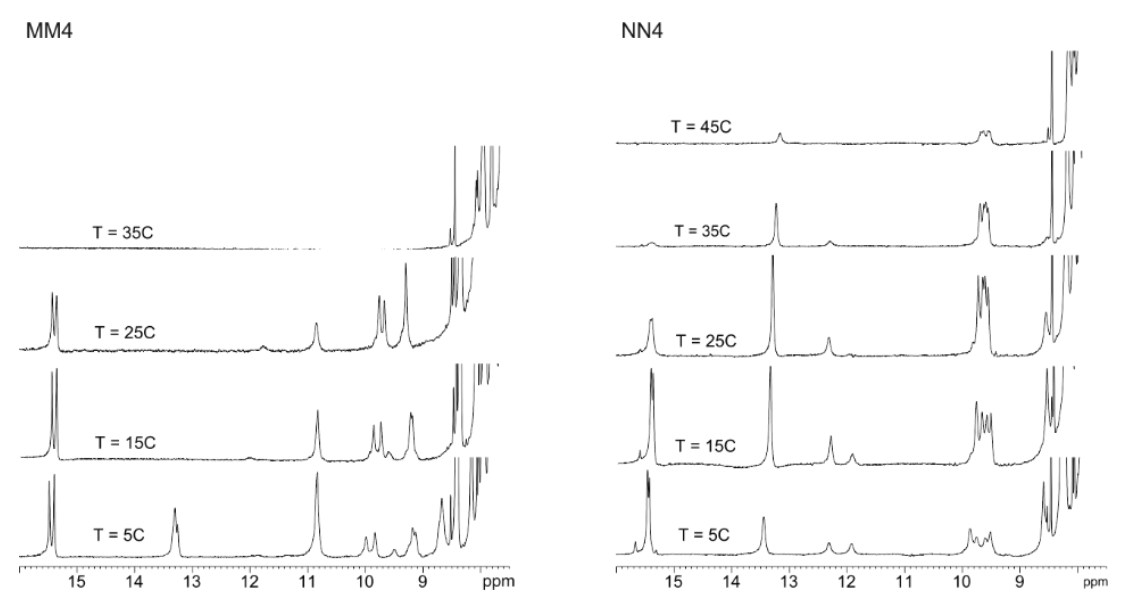

Figure S14. NMR melting experiments at pH 7 (phosphate buffer, [oligonucleotide]=1 mM) of MM4 and NN4. 

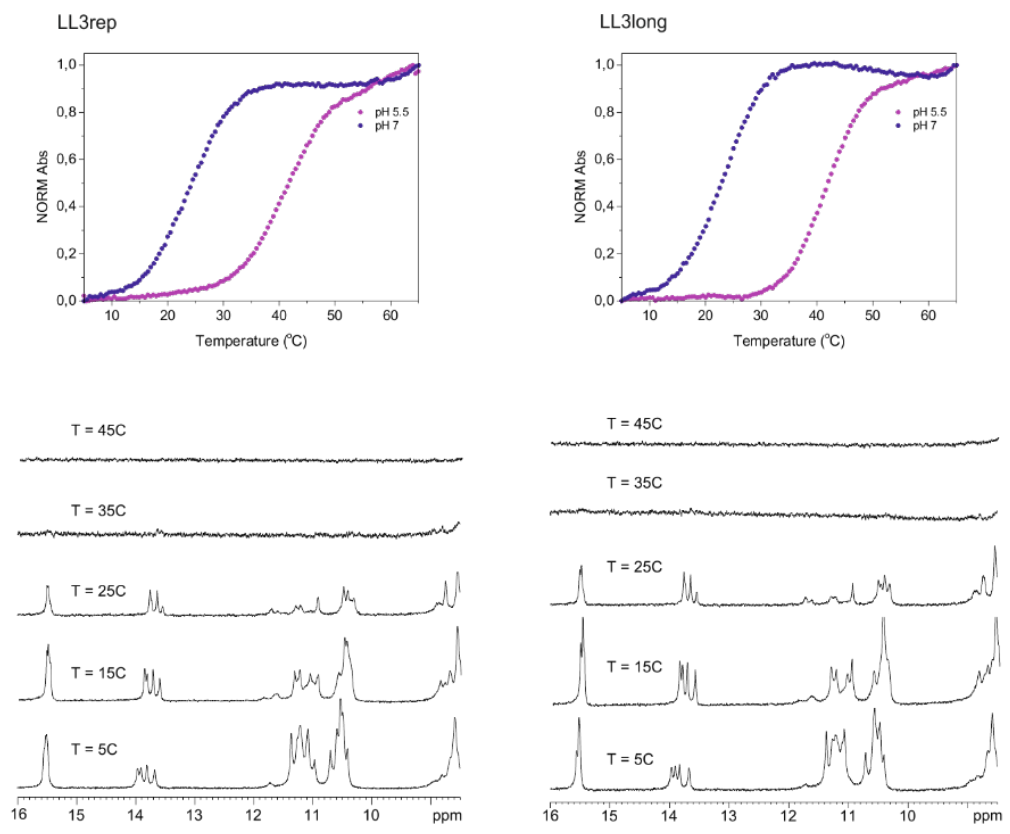

Figure S15. UV melting curves [oligonucleotide] $=3,5 \mu \mathrm{M}, 25 \mathrm{mM}$ cacodylate buffer at different $\mathrm{pH}$ and NMR melting experiments at pH 7 (phosphate buffer, [oligonucleotide]=1 mM) of LL3rep (left) and LL3long (right).
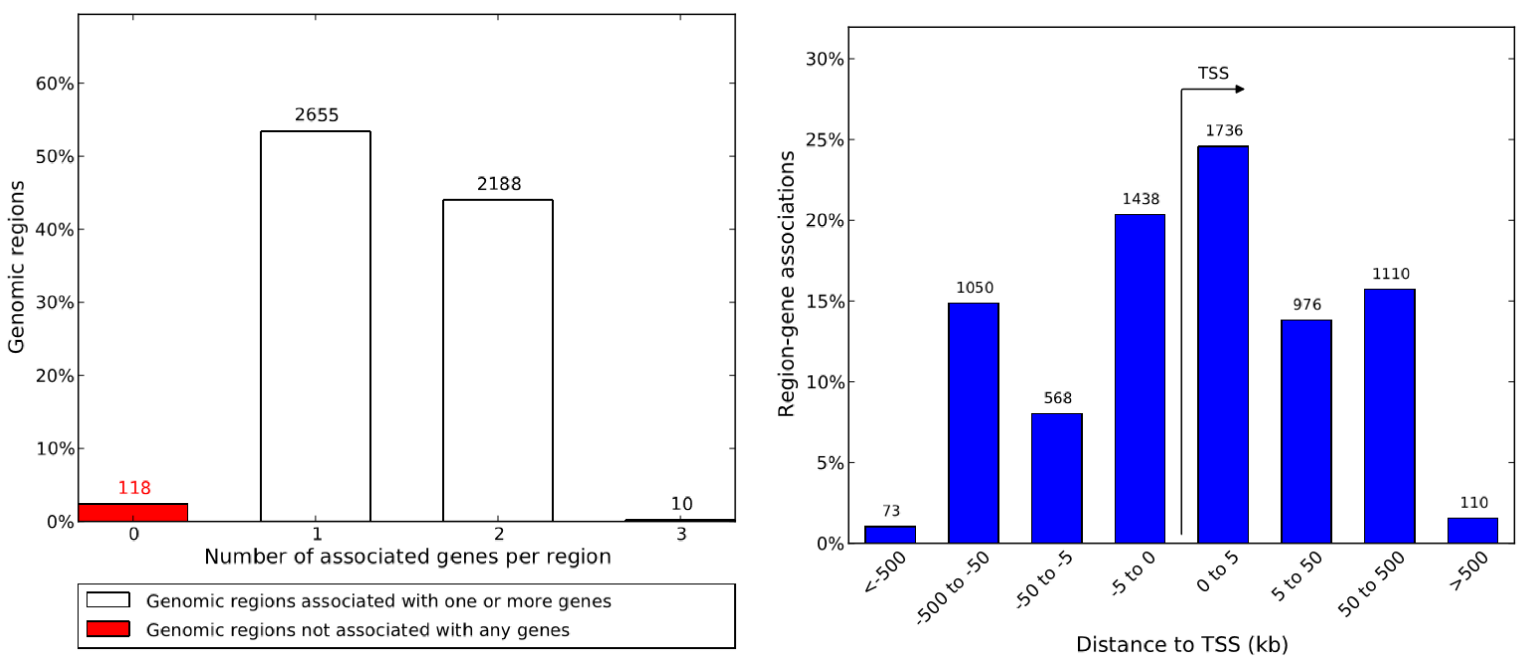

Figure S16. Annotation of regions with the consensus motif using Genomic Regions Enrichment Annotations (GREAT) Tool. Left: Number of hits associated to $0,1,2$ or 3 genes, taking minimum distance upstream ( $5 \mathrm{~kb})$ and downstream (1kb) of the TSS. The number of hits not associated to any gene (118) is more than five times lower than the expected number indicating the concentration of i-motifs close to genes. Right: The bar chart shows the distribution of distances between hits and TSS of their associated genes. The hyper-concentration of i-motif-forming regions close to the origin of genes is very clear. 
Table S1. Dose-response fitting values of CD-monitored pH titration for LL3, LL4, LL3long and LL3rep.

\begin{tabular}{|c|c|c|c|c|c|c|c|c|}
\hline \multirow{2}{*}{ Sequence } & \multicolumn{2}{|c|}{$\varepsilon_{\text {folded }}$} & \multicolumn{2}{c|}{$\varepsilon_{\text {unfolded }}$} & \multicolumn{2}{c|}{ pH $_{\text {T }}$} & \multicolumn{2}{c|}{$\begin{array}{c}\text { Cooperativity } \\
\text { parameter (Hill slope) }\end{array}$} \\
\cline { 2 - 9 } & Value & $\begin{array}{c}\text { Stand. } \\
\text { Error }\end{array}$ & Value & $\begin{array}{c}\text { Stand. } \\
\text { Error }\end{array}$ & Value & $\begin{array}{c}\text { Stand. } \\
\text { Error }\end{array}$ & Value & $\begin{array}{c}\text { Stand. } \\
\text { Error }\end{array}$ \\
\cline { 2 - 9 }$y$ & 0.96387 & 0.00525 & 0.00622 & 0.00576 & 7.76202 & 0.00623 & -2.84909 & 0.11266 \\
\hline LL3 & 0.92324 & 0.00442 & 0.00449 & 0.00495 & 7.94836 & 0.00697 & -1.93829 & 0.05096 \\
\hline LL3long & 0,97752 & 0,008 & $4,243 \mathrm{E}-4$ & 0,00716 & 7,48845 & 0,0093 & $-3,17191$ & 0,1794 \\
\hline LL3rep & 0,96105 & 0,01154 & 0,02011 & 0,0112 & 7,55787 & 0,01436 & $-2,62543$ & 0,19116 \\
\hline
\end{tabular}

Table S2. Chemical shifts of LL4-M1, pH 7, T=5 ${ }^{\circ} \mathrm{C}$.

\begin{tabular}{|l|c|c|c|c|c|c|c|c|c|c|c|}
\hline Residue & H1/H3 $^{+}$ & H42/H22 & H41/H21 & H6/H8 & H5/Me & H1' & H2' & H2' & H3' $^{\prime}$ & H4' $^{\prime}$ & H5'/H5' $^{\prime}$ \\
\hline T1 & n. o. & - & - & 7.80 & 1.94 & 6.39 & 2.43 & 2.59 & & & \\
\hline m C2 & 15.40 & 9.55 & 7.82 & 7.45 & 2.01 & 6.32 & 1.20 & 2.20 & & & \\
\hline G3 & 11.13 & 8.59 & 5.82 & 8.24 & - & 5.92 & 2.94 & 2.67 & & & \\
\hline T4 & n. o. & - & - & 7.63 & 1.74 & 6.13 & 2.03 & 2.30 & & & \\
\hline T5/T18 & n. o. & - & - & 7.84 & 1.93 & 6.48 & 2.32 & 2.54 & 4.63 & 4.56 & $4.17,3.95$ \\
\hline C6 & - & 8.57 & 7.40 & 7.87 & 6.09 & 6.28 & \multicolumn{2}{|c|}{2.45} & 4.81 & 4.34 & 4.17 \\
\hline C7 & 15.44 & 10.45 & 8.16 & 7.36 & 5.92 & 6.20 & 0.73 & 2.09 & & & \\
\hline G8 & 13.71 & 7.99 & 7.70 & 8.29 & - & 5.99 & 3.02 & 2.69 & & & \\
\hline T9 & n. o. & - & - & 7.59 & 1.72 & 5.85 & 2.15 & 2.38 & & & \\
\hline T10 & n. o. & - & - & 7.66 & 1.76 & 6.17 & 2.29 & 2.45 & & & \\
\hline T14 & n. o. & - & - & 7.79 & 1.89 & 6.85 & 2.49 & 2.63 & & & \\
\hline C15 & 15.44 & 8.71 & 7.53 & 7.58 & 6.29 & 6.33 & 1.05 & 2.19 & & & \\
\hline G16 & 10.66 & 8.62 & 5.67 & 8.51 & - & 5.94 & 2.94 & 2.66 & & & \\
\hline T17 & n. o. & - & - & 7.63 & 1.79 & 6.13 & 2.03 & 2.30 & & & \\
\hline C19 & - & 8.58 & 7.41 & 7.87 & 6.09 & 6.28 & 2.45 & 4.81 & 4.34 & 4.17 \\
\hline C20 & 15.40 & 10.07 & 7.91 & 7.35 & 5.89 & 6.20 & 1.37 & 2.17 & & & \\
\hline G21 & 13.78 & 8.00 & 6.62 & 8.28 & - & 6.01 & 3.02 & 2.68 & & & \\
\hline T22 & n. o. & - & - & 7.65 & 1.76 & 6.03 & 2.12 & 2.25 & & & \\
\hline
\end{tabular}

no: not observed, na: not assigned.

T11, T12 and T13 cannot be unambiguously assigned.

Table S3. Chemical shifts of LL4-M2, pH 7, T=5 ${ }^{\circ} \mathrm{C}$.

\begin{tabular}{|c|c|c|c|c|c|c|c|c|}
\hline Residue & $\mathrm{H} 1 / \mathrm{H3}^{+}$ & H42/H22 & H41/H21 & H6/H8 & $\mathrm{H} 5 / \mathrm{Me}$ & H1' & H2' & H2" \\
\hline${ }^{\mathrm{m}} \mathrm{C} 2{ }^{\mathrm{m}} \mathrm{C} 15$ & $15.39 / 15.37$ & 9.20 & $7.62 / 7.42$ & $7.45 / 7.41$ & $1.91 / 1.96$ & 6.31 & $1.10 / 1.17$ & $2.16 / 2.22$ \\
\hline G3/G16 & $11.15 / 11.08$ & 8.56 & $5.81 / 5.59$ & $8.19 / 8.23$ & - & 5.91 & 2.94 & 2.67 \\
\hline Т4/T9/Т17/Т22 & no & - & - & 7.64 & 1.76 & na & na & na \\
\hline C6/C19 & - & 8.58 & 7.39 & 7.86 & 6.08 & 6.28 & \multicolumn{2}{|c|}{2.44} \\
\hline $\mathrm{C} 7 / \mathrm{C} 2 \mathrm{O}$ & $15.39 / 15.37$ & 10.35 & 8.11 & 7.35 & 5.91 & 6.20 & 0.73 & 2.15 \\
\hline G8/G21 & 13.76 & 7.98 & 7.66 & 8.29 & - & 6.02 & 3.04 & 2.71 \\
\hline
\end{tabular}

no: not observed, na: not assigned. 


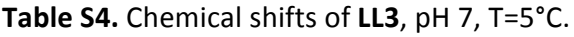

\begin{tabular}{|c|c|c|c|c|c|c|c|c|c|c|}
\hline Residue & $\mathrm{H} 1 / \mathrm{H3}^{+}$ & H42/H22 & H41/H21 & H6/H8 & $\mathrm{H} 5 / \mathrm{Me}$ & $\mathrm{H1}^{\prime}$ & $\mathrm{H} 2^{\prime}$ & H2" & H3' & H4' \\
\hline T1 & 11.40 & - & - & 7.84 & 1.93 & 6.47 & 2.35 & 2.53 & & \\
\hline $\mathrm{C} 2$ & 15.48 & 8.62 & 7.28 & 7.44 & 6.11 & 6.32 & 1.06 & 2.26 & & \\
\hline G3 & 10.26 & 8.60 & 5.84 & 8.31 & - & 5.94 & 2.93 & 2.66 & & \\
\hline T4 & no & - & - & 7.62 & 1.75 & 6.13 & na & na & & \\
\hline T5/T17 & no & - & - & 7.84 & 1.94 & 6.13 & na & na & & \\
\hline C6 & - & 8.59 & 7.46 & 7.93 & 6.13 & 6.30 & \multicolumn{2}{|c|}{2.44} & & \\
\hline C7 & 15.55 & 10.66 & 8.19 & 7.45 & 5.95 & 6.27 & 0.78 & 2.09 & & \\
\hline G8 & 13.94 & 8.20 & 7.63 & 8.32 & - & 6.03 & 3.06 & 2.69 & & \\
\hline T9 & no & - & - & 7.63 & 1.69 & 5.93 & na & na & & \\
\hline T10 & no & - & - & 7.76 & na & 5.54 & na & na & & \\
\hline T11 & no & - & - & na & 1.99 & na & na & na & & \\
\hline T12 & no & - & - & 7.84 & 1.99 & na & na & na & & \\
\hline T13 & 11.20 & - & - & 7.74 & 1.71 & 6.12 & 2.46 & 2.63 & & \\
\hline C14 & 15.55 & 8.66 & 6.97 & 7.49 & 6.39 & 6.41 & 1.07 & 2.17 & & \\
\hline G15 & no & 9.07 & 5.30 & 8.39 & - & 5.99 & 2.99 & 2.70 & & \\
\hline T16 & no & - & - & 7.64 & 1.81 & 6.08 & na & na & & \\
\hline C18 & - & 8.55 & 7.43 & 7.93 & 6.13 & 6.30 & \multicolumn{2}{|c|}{2.44} & & \\
\hline C19 & 15.48 & 10.62 & 8.05 & 7.41 & 5.95 & 6.23 & 0.76 & 2.02 & 4.70 & 4.50 \\
\hline G20 & 13.65 & 7.96 & 7.67 & 8.27 & - & 5.98 & 3.04 & 2.66 & & \\
\hline T21 & no & - & - & 7.63 & 1.73 & 5.96 & na & na & & \\
\hline
\end{tabular}

no: not observed, na: not assigned.

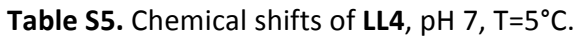

\begin{tabular}{|c|c|c|c|c|c|c|c|c|c|c|}
\hline Residue & ${\mathrm{H} 1 / \mathrm{H3}^{+}}^{+}$ & H42/H22 & H41/H21 & H6/H8 & H5/Me & $H 1^{\prime}$ & $\mathrm{H} 2^{\prime}$ & H2" & H3' & H4' \\
\hline T1 & 11.49 & - & - & 7.76 & 1.83 & 6.45 & na & na & & \\
\hline $\mathrm{C2}$ & 15.47 & 8.82 & 7.38 & 7.46 & 6.11 & 6.35 & 1.07 & 2.27 & 4.80 & \\
\hline G3 & 10.28 & 8.60 & 5.93 & 8.32 & - & 5.95 & 2.94 & 2.66 & 5.08 & 4.69 \\
\hline T4 & 10.48 & - & - & 7.63 & 1.77 & na & na & na & & \\
\hline T5/T18 & no & - & - & 7.85 & 1.93 & 6.48 & 2.29 & 2.55 & & \\
\hline C6 & - & 8.57 & 7.41 & 7.92 & 6.13 & 6.30 & \multicolumn{2}{|c|}{2.44} & 4.67 & 4.21 \\
\hline C7 & 15.51 & 10.72 & 8.20 & 7.43 & 5.95 & 6.28 & 0.79 & 2.12 & 4.71 & \\
\hline G8 & 13.91 & 8.16 & 7.63 & 8.33 & - & 6.02 & 3.06 & 2.70 & 5.15 & 4.61 \\
\hline T9 & 10.54 & - & - & 7.64 & 1.69 & 5.94 & 2.43 & 2.52 & & \\
\hline T14 & 11.24 & - & - & 7.78 & 1.92 & 6.13 & 2.44 & 2.58 & & \\
\hline C15 & 15.51 & 8.60 & 6.96 & 7.49 & 6.33 & 6.41 & 1.10 & 2.20 & 4.81 & \\
\hline G16 & 12.09 & 9.04 & 5.32 & 8.30 & - & 5.99 & 2.98 & 2.70 & 5.08 & 4.69 \\
\hline T17 & 10.51 & - & - & 7.64 & 1.80 & na & na & na & & \\
\hline C19 & - & 8.57 & 7.43 & 7.92 & 6.15 & 6.29 & \multicolumn{2}{|c|}{2.44} & 4.67 & 4.21 \\
\hline $\mathrm{C2O}$ & 15.47 & 10.42 & 8.00 & 7.41 & 5.94 & 6.23 & 0.79 & 2.05 & 4.71 & \\
\hline G21 & 13.66 & 8.00 & 7.64 & 8.28 & - & 5.99 & 3.03 & 2.66 & 5.14 & 4.67 \\
\hline T22 & 10.55 & - & - & 7.63 & 1.75 & 5.92 & 2.03 & 2.15 & 4.29 & \\
\hline
\end{tabular}

no: not observed, na: not assigned.

T10, T11, T12 and T13 cannot be unambiguously assigned. 
Table S6. Experimental constraints and calculation statistics of LL3.

\begin{tabular}{|c|c|c|}
\hline \multicolumn{3}{|c|}{ Experimental distance constraints } \\
\hline Total number & \multicolumn{2}{|c|}{125} \\
\hline intra-residue & \multicolumn{2}{|c|}{47} \\
\hline sequential & \multicolumn{2}{|c|}{41} \\
\hline range $>1$ & \multicolumn{2}{|c|}{37} \\
\hline \multicolumn{3}{|l|}{ RMSD ( $\AA$ ) } \\
\hline all well-defined ${ }^{*}$ bases & \multicolumn{2}{|c|}{$0.5 \pm 0.1$} \\
\hline all well-defined ${ }^{*}$ heavy atoms & \multicolumn{2}{|c|}{$0.8 \pm 0.2$} \\
\hline backbone & \multicolumn{2}{|c|}{$1.7 \pm 0.4$} \\
\hline all heavy atoms & \multicolumn{2}{|c|}{$2.8 \pm 0.7$} \\
\hline Residual violations & Average & Range \\
\hline Sum of violation $(\AA ̊)$ & 1.23 & $0.84 \ldots 1.69$ \\
\hline Max. violation (Å) & 0.22 & $0.28 \ldots 0.16$ \\
\hline NOE energy" (kcal/mol) & 5.59 & $4.65 \ldots 6.60$ \\
\hline Total energy (kcal/mol) & -1517 & $-1717 \ldots-1334$ \\
\hline \multicolumn{3}{|l|}{$\begin{array}{l}{ }^{*} \text { All except thymines } 5,10,11,12,17 \\
{ }^{*} \mathrm{~K}_{\mathrm{NOE}}=20 \mathrm{kcal} /\left(\mathrm{mol} \cdot \AA^{2}\right)\end{array}$} \\
\hline
\end{tabular}


Table S7. Average dihedral angles and order parameters of the dimeric structure of LL3.

\begin{tabular}{|c|c|c|c|c|c|c|c|c|c|c|c|c|c|c|c|c|}
\hline \multirow{2}{*}{ Residue } & \multicolumn{2}{|c|}{ Pseudorot. } & \multicolumn{2}{|l|}{$\alpha$} & \multicolumn{2}{|l|}{$\beta$} & \multicolumn{2}{|l|}{$\mathbf{Y}$} & \multicolumn{2}{|l|}{$\delta$} & \multicolumn{2}{|l|}{$\varepsilon$} & \multicolumn{2}{|l|}{$\zeta$} & \multicolumn{2}{|l|}{$x$} \\
\hline & Phase & Ampli. & Averag. & OP & Averag. & OP & Averag. & OP & Averag. & OP & Averag. & OP & Averag. & OP & Averag. & OP \\
\hline T1 & 64 & 31 & - & - & - & - & 4 & 1.0 & 6 & 1.0 & 2 & 1.0 & - & - & 5 & 1.0 \\
\hline C2 & 137 & 40 & 48 & 0.8 & 4 & 1.0 & 44 & 0.8 & 9 & 1.0 & 6 & 1.0 & 2 & 1.0 & 6 & 1.0 \\
\hline G3 & 166 & 36 & 6 & 1.0 & 4 & 1.0 & 3 & 1.0 & 2 & 1.0 & 17 & 1.0 & 5 & 1.0 & 6 & 1.0 \\
\hline T4 & 166 & 36 & 11 & 1.0 & 9 & 1.0 & 5 & 1.0 & 1 & 1.0 & 27 & 0.9 & 13 & 1.0 & 5 & 1.0 \\
\hline T5 & 153 & 39 & 84 & 0.3 & 23 & 0.9 & 55 & 0.7 & 9 & 1.0 & 28 & 0.9 & 16 & 1.0 & 12 & 1.0 \\
\hline C6 & 73 & 29 & 88 & 0.3 & 9 & 1.0 & 54 & 0.7 & 20 & 0.9 & 47 & 0.7 & 85 & 0.4 & 10 & 1.0 \\
\hline C7 & 153 & 41 & 44 & 0.8 & 21 & 0.9 & 47 & 0.8 & 4 & 1.0 & 3 & 1.0 & 48 & 0.7 & 5 & 1.0 \\
\hline G8 & 150 & 35 & 2 & 1.0 & 1 & 1.0 & 1 & 1.0 & 3 & 1.0 & 7 & 1.0 & 3 & 1.0 & 3 & 1.0 \\
\hline T9 & 166 & 33 & 6 & 1.0 & 7 & 1.0 & 3 & 1.0 & 4 & 1.0 & 40 & 0.8 & 7 & 1.0 & 5 & 1.0 \\
\hline T10 & 142 & 41 & 72 & 0.5 & 49 & 0.7 & 65 & 0.6 & 12 & 1.0 & 40 & 0.8 & 66 & 0.6 & 82 & 0.6 \\
\hline T11 & 147 & 41 & 95 & 0.0 & 14 & 1.0 & 93 & 0.2 & 10 & 1.0 & 49 & 0.7 & 83 & 0.5 & 92 & 0.2 \\
\hline T12 & 133 & 39 & 68 & 0.6 & 21 & 0.9 & 38 & 0.9 & 14 & 1.0 & 34 & 0.9 & 75 & 0.6 & 8 & 1.0 \\
\hline T13 & 156 & 30 & 73 & 0.6 & 12 & 1.0 & 33 & 0.9 & 8 & 1.0 & 5 & 1.0 & 47 & 0.7 & 3 & 1.0 \\
\hline C14 & 169 & 31 & 8 & 1.0 & 2 & 1.0 & 4 & 1.0 & 4 & 1.0 & 4 & 1.0 & 17 & 1.0 & 5 & 1.0 \\
\hline G15 & 164 & 36 & 4 & 1.0 & 1 & 1.0 & 4 & 1.0 & 3 & 1.0 & 14 & 1.0 & 2 & 1.0 & 1 & 1.0 \\
\hline T16 & 165 & 36 & 6 & 1.0 & 7 & 1.0 & 3 & 1.0 & 2 & 1.0 & 28 & 0.9 & 10 & 1.0 & 1 & 1.0 \\
\hline T17 & 157 & 40 & 65 & 0.6 & 6 & 1.0 & 97 & 0.1 & 7 & 1.0 & 40 & 0.8 & 7 & 1.0 & 21 & 0.9 \\
\hline C18 & 117 & 33 & 66 & 0.6 & 20 & 1.0 & 71 & 0.6 & 11 & 1.0 & 33 & 0.9 & 11 & 1.0 & 11 & 1.0 \\
\hline C19 & 133 & 41 & 53 & 0.7 & 17 & 1.0 & 52 & 0.7 & 20 & 0.9 & 44 & 0.8 & 34 & 0.9 & 10 & 1.0 \\
\hline G20 & 165 & 31 & 24 & 0.9 & 4 & 1.0 & 4 & 1.0 & 5 & 1.0 & 30 & 0.9 & 50 & 0.8 & 5 & 1.0 \\
\hline T21 & 164 & 34 & 15 & 1.0 & 8 & 1.0 & 2 & 1.0 & 2 & 1.0 & - & - & 23 & 0.9 & 3 & 1.0 \\
\hline
\end{tabular}

Table S8. Genomic annotation of hits. Enrichment of hits for each category is computed as the ratio between the normalized number of hits (number of hits in a category divided by the total number of regions) and the normalized number of base-pairs per region type (percentage of base-pairs of the genome per category). Genomic sequences shorter than $1 \mathrm{Mbp}$ were excluded to reduce noise. Note again the over-representation of i-motif-forming sequences in regulatory regions (promoter and 5UTR) and the under-representation in intron or intergenic regions.

\begin{tabular}{|lccc|}
\hline Annotation & Number of hits & Total size (bp) & Log2 Enrichment \\
\hline 3UTR & 28 & 23005177 & -0.384 \\
ncRNA & 17 & 6409543 & 0.74 \\
pseudo & 11 & 2010139 & 1.785 \\
Exon & 358 & 36768443 & 2.616 \\
Intron & 1239 & 1240886382 & -0.669 \\
Intergenic & 841 & 1749354789 & -1.724 \\
Promoter & 2129 & 35414190 & 5.243 \\
5UTR & 264 & 2760547 & 5.912 \\
\hline
\end{tabular}


Table S9. GO Enrichment analysis. Functional annotation terms significantly enriched at hits of the consensus motif as discovered by GREAT. For each term we report the $p$-value corrected for multiple testing (FDR $p$-value), the ratio of observed/expected regions with the annotation (Fold Enrichment) and the number of regions mapped to genes associated to the GO term.

\begin{tabular}{|llll|}
\hline Term Name & FDR p-value & $\begin{array}{l}\text { Fold } \\
\text { Enrichment }\end{array}$ & $\begin{array}{l}\text { Observed Region } \\
\text { Hits }\end{array}$ \\
\hline regulation of metanephric glomerulus development & $7.94876 \mathrm{e}-23$ & 10.4771 & 38 \\
positive regulation of kidney development & $2.36364 \mathrm{e}-6$ & 2.8127 & 39 \\
enteric nervous system development & $2.77212 \mathrm{e}-6$ & 2.5710 & 45 \\
Rac protein signal transduction & $8.82346 \mathrm{e}-5$ & 2.8911 & 28 \\
phospholipid translocation & $1.16460 \mathrm{e}-4$ & 2.6258 & 32 \\
intrinsic apoptotic signaling pathway in response to & $2.04422 \mathrm{e}-3$ & 2.7949 & 21 \\
endoplasmic reticulum stress & $2.65032 \mathrm{e}-3$ & 2.8223 & 20 \\
paraxial mesoderm morphogenesis & $4.54575 \mathrm{e}-3$ & 2.8760 & 18 \\
corpus callosum development & $2.48624 \mathrm{e}-2$ & 2.1246 & 24 \\
paraxial mesoderm development & $3.17901 \mathrm{e}-2$ & 4.7062 & 7 \\
negative regulation of protein kinase activity by & & & \\
regulation of protein phosphorylation & & & \\
\hline
\end{tabular}

Table S10. Synthesis results for LL3 and LL4.

\begin{tabular}{|ccccccc|}
\hline Sequence & $\begin{array}{c}\varepsilon \\
\left(\mathrm{mL} \cdot \mu \mathrm{mol}^{-1} \cdot \mathrm{cm}^{-1}\right)\end{array}$ & $\begin{array}{c}\text { Crude Yield } \\
\%\end{array}$ & $\begin{array}{c}\text { HPLC } \\
\text { Purity } \%\end{array}$ & $\begin{array}{c}\text { Purified } \\
\text { Yield } \%\end{array}$ & $\begin{array}{c}\text { Theoretical } \\
\text { Mass }\end{array}$ & $\begin{array}{c}\text { MS-MALDI-TOF } \\
\mathrm{m} / \mathrm{z}\end{array}$ \\
\hline LL3 & 178.1 & 86 & 78 & 37 & 6336.1 & 6333.9 \\
LL4 & 186.2 & 84 & 69 & 26 & 6640.1 & 6639.4 \\
\hline
\end{tabular}

\section{References}

(1) Plateau, P.; Guéron, M. J. Am. Chem. Soc. 1982, 104 (25), 7310.

(2) Kumar, A.; Ernst, R. R.; Wüthrich, K. Biochem. Biophys. Res. Commun. 1980, 95 (1), 1.

(3) Bax, A.; Davis, D. G. J. Magn. Reson. 1985, 65 (2), 355.

(4) Piotto, M.; Saudek, V.; Sklenář, V. J. Biomol. NMR 1992, 2 (6), 661.

(5) Cai, L.; Chen, L.; Raghavan, S.; Rich, A.; Ratliff, R.; Moyzis, R. Nucleic Acids Res. 1998, 26 (20), 4696.

(6) Güntert, P.; Mumenthaler, C.; Wüthrich, K. J. Mol. Biol. 1997, 273 (1), 283.

(7) D.A. Case, T.A. Darden, T.E. Cheatham, III, C.L. Simmerling, J. Wang, R.E. Duke, R. Luo, R.C. Walker, W. Zhang, K.M. Merz, B. Roberts, S. Hayik, A. Roitberg, G. Seabra, J. Swails, A.W. Götz, I. Kolossváry, K.F. Wong, F. Paesani, J. Vanicek, R.M. Wolf, J. Liu, X. Wu, S.R. Brozell, T. Steinbrecher, H. Gohlke, Q. Cai, X. Ye, J. Wang, M.-J. Hsieh, G. Cui, D.R. Roe, D.H. Mathews, M.G. Seetin, R. Salomon-Ferrer, C. Sagui, V. Babin, T. Luchko, S. Gusarov, A. Kovalenko, and P.A. Kollman 2012, AMBER 12, University of California, San Francisco.

(8) Soliva, R.; Monaco, V.; Gómez-Pinto, I.; Meeuwenoord, N. J.; Marel, G. a; Boom, J. H.; González, C.; Orozco, M. Nucleic Acids Res. 2001, 29 (14), 2973.

(9) Ivani, I.; Dans, P. D.; Noy, A.; Pérez, A.; Faustino, I.; Hospital, A.; Walther, J.; Andrio, P.; Goñi, R.; Balaceanu, A.; Portella, G.; Battistini, F.; Gelpí, J. L.; González, C.; Vendruscolo, M.; Laughton, C. A.; Harris, S. A.; Case, D. A.; Orozco, M. Nat. Methods 2015, $13(1), 55$.

(10) Koradi, R.; Billeter, M.; Wüthrich, K. J. Mol. Graph. 1996, 14 (1), 51. 